\title{
Inorganic Nanoparticles Applied for Active Targeted Photodynamic Therapy of Breast Cancer
}

\author{
Hanieh Montaseri (D, Cherie Ann Kruger*(D) and Heidi Abrahamse (D) \\ Laser Research Centre, Faculty of Health Sciences, University of Johannesburg, P.O. Box 17011, \\ Doornfontein 2028, South Africa; montaseri.hanieh@gmail.com (H.M.); habrahamse@uj.ac.za (H.A.) \\ * Correspondence: cherier@uj.ac.za; Tel.: +27-11-559-6860
}

Citation: Montaseri, H.; Kruger, C.A.; Abrahamse, H. Inorganic Nanoparticles Applied for Active Targeted Photodynamic Therapy of Breast Cancer. Pharmaceutics 2021, 13, 296. https://doi.org/10.3390/ pharmaceutics13030296

Academic Editor: Anna Angela Barba

Received: 26 January 2021

Accepted: 15 February 2021

Published: 24 February 2021

Publisher's Note: MDPI stays neutral with regard to jurisdictional claims in published maps and institutional affiliations.

Copyright: (c) 2021 by the authors. Licensee MDPI, Basel, Switzerland. This article is an open access article distributed under the terms and conditions of the Creative Commons Attribution (CC BY) license (https:// creativecommons.org/licenses/by/ $4.0 /)$.

\begin{abstract}
Photodynamic therapy (PDT) is an alternative modality to conventional cancer treatment, whereby a specific wavelength of light is applied to a targeted tumor, which has either a photosensitizer or photochemotherapeutic agent localized within it. This light activates the photosensitizer in the presence of molecular oxygen to produce phototoxic species, which in turn obliterate cancer cells. The incidence rate of breast cancer (BC) is regularly growing among women, which are currently being treated with methods, such as chemotherapy, radiotherapy, and surgery. These conventional treatment methods are invasive and often produce unwanted side effects, whereas PDT is more specific and localized method of cancer treatment. The utilization of nanoparticles in PDT has shown great advantages compared to free photosensitizers in terms of solubility, early degradation, and biodistribution, as well as far more effective intercellular penetration and uptake in targeted cancer cells. This review gives an overview of the use of inorganic nanoparticles (NPs), including: gold, magnetic, carbon-based, ceramic, and up-conversion NPs, as well as quantum dots in PDT over the last 10 years (2009 to 2019), with a particular focus on the active targeting strategies for the PDT treatment of BC.
\end{abstract}

Keywords: Breast cancer treatment; Photodynamic therapy; Inorganic nanoparticles; Active targeting

\section{Introduction}

Breast cancer $(\mathrm{BC})$ is the most prevalent malignancy among women worldwide [1]. Cisplatin (cis-diammine-dichloroplatinum (II)) is currently an approved drug that can be utilized for the treatment of various cancers, since it inhibits DNA replication and chain elongation [1]. Although numerous anticancer drugs have been developed over the years for BC treatment, it still remains a therapeutic challenge; since BC can metastasis, become resistant to certain drugs, as well as exhibit lesions of recurrence after surgery [2]. More importantly, conventional anticancer drugs, when administered, spread throughout the body, and thus affect healthy cells and tissues, instead of just the localized tumor area, which requires treatment [3].

The effectiveness of photodynamic therapy (PDT) in ablating localized BC tumors, with limited side-effects is a significant breakthrough in unconventional treatments [4]. PDT can be performed as an adjuvant to other therapies, since it enables selective, as well as localized damage to tumors and their surrounding vasculature [4]. PDT is based on the activation of a nontoxic photosensitizer (PS) with an appropriate light to produce reactive oxygen species (ROS), which in turn eradicates cancer cells [4]. However, due to the hydrophobic nature of most PSs, they have high tendency to aggregate in aqueous solution, reducing the efficacy of PDT treatment [5]. In addition, PSs do not tend to bind to tumor cells selectively, resulting in poor specificity uptake in cancer cells and so localized normal tissues can become affected during treatment [6]. In this context, the combination of nanotechnology and PDT in the form of nanoplatforms is of great importance, whereby PSs are covalently or non-covalently bound to the nanoparticles (NPs) [6]. The selectivity of 
the nano delivery agents can be also enhanced using active targeting, whereby antibodies and small ligands can be bound to NPs, and so allow for PSs to be specifically (as well as directly) delivered into targeted tumor cells [6]. Therefore, the aim of this review is to collate and discuss the types of inorganic NPs that have been used for the active (as well as targeted) delivery of PSs within PDT BC treatment.

\section{Conventional Treatments of Breast Cancer}

Chemotherapy, surgery, and radiotherapy are the main therapies utilized for small sized BC tumors [7]. Some other less invasive treatments, such as cryotherapy, laser ablation, and radiofrequency ablation (RFA), have also been developed for early stage $\mathrm{BC}[8,9]$. In spite of promising developments in the treatment of early $\mathrm{BC}$, surgery is generally the first option. Often, positive BC tumor margins can remain unresected, and so the possibility of reoccurrence is eminent. Thus, most often, patients require additional surgeries and chemotherapy treatments $[10,11]$. In this context, new (and far more effective) treatment modalities are sought after in order to mitigate the collateral damage, as well as improve the treatment outcomes of BC.

\section{Photodynamic Therapy (PDT) and Photosensitizers (PSs)}

PDT is an alternative non-invasive therapeutic technique for the treatment of various types of cancers and non-oncological diseases [4]. PDT is painless and its selectivity to cancer cells is well tolerated by patients [12]. It involves three main aspects: (1) a photo active compound or PS that accumulates in neoplastic cells; (2) local light to excite and activate the PS; as well as (3) surrounding tumor molecular oxygen [13]. When a PS becomes activated through illumination at an appropriate wavelength and it reacts with surrounding molecular oxygen, it produces reactive oxygen species (ROS) and singlet oxygen, which destroys localized tumor cells [13].

Among the broad spectrum of light, ultraviolet (UV) light (200-400 nm) may damage biological components, and so its biomedical applications are restrained, while visible light in the range of $400-650 \mathrm{~nm}$ can be utilized for activation of various PSs [13]. In addition, "biological transparent windows" in near infrared (NIR)-I (750-1000 nm) and NIR-II window (1000-1700 nm) enjoy low absorption and scattering, with deep tissue penetration and low auto-fluorescence from biological tissues, and so can be utilized for biophotonic imaging $[14,15]$.

Tissue penetration depth of light can be sometimes limiting, which can affect the amount of PS activated, which in turn affects the amount of ROS and singlet oxygen produced to kill tumor cells [16]. Short wavelengths $(<650 \mathrm{~nm})$ generally have a lower penetration depth in tissues, while longer wavelength (above $850 \mathrm{~nm}$ ) ranges are not sufficient enough to excited or activate PSs [16]. Thus, the most appropriate wavelength for PDT is between the range of 600 and $850 \mathrm{~nm}$, which is known as the "phototherapeutic window" (Figure 1) [16].

The most effective PSs in PDT cancer applications are chemically pure and stable, as well as have minimal dark toxicity and side effects, with ideal hydrophilic properties [17]. Additionally, PSs should have strong absorption within the range of $600-850 \mathrm{~nm}$, as to ensure, limited scattering, high tissue depth penetration, with maximum extinction coefficients [17].

Hematoporphyrin derivative $(\mathrm{HpD})$ and photofrin are the first-generation commercial PSs, known for harsh PDT unwanted side effects [18]. While aminolevulinic acid (ALA), esterified derivatives of ALA and phthalocyanine compounds, which are considered second generation PSs, are known to produce minimal PDT side effects, with improved ROS generation, due to their longer absorption wavelengths, with improved tissue depth penetration [18]. Moreover, conjugation of second generation PSs to various biological carriers (such as nanoparticles) are referred to as third generation PSs, since these "carrier" conjugations generally allow PSs to selectively accumulate in cancer cells [19]. 
Thus, the activation wavelength, solubility, octanol/water partition coefficient, and molar extinction coefficient are of great importance for determining the potency of a PS in PDT. The main parameters of some PSs are compared in Table S1.

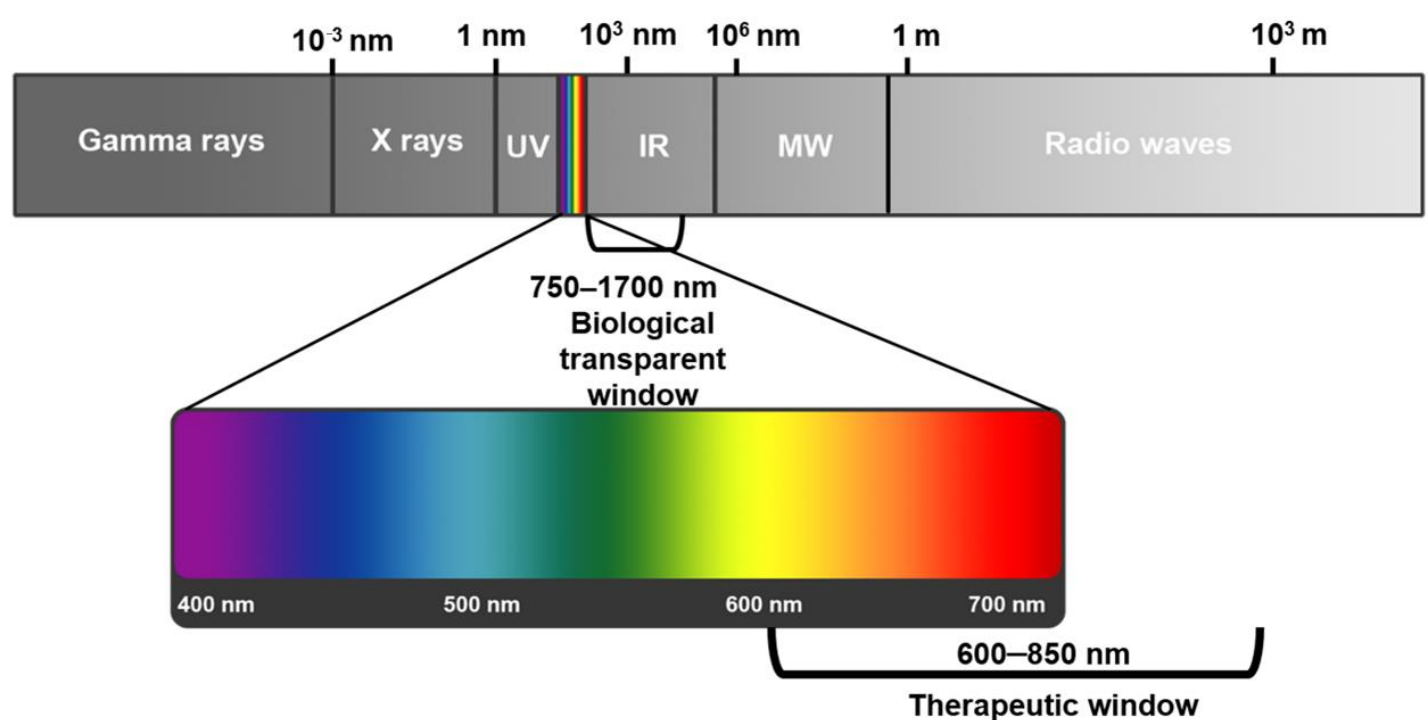

Figure 1. Electromagnetic spectrum showing the ideal phototherapeutic window for photodynamic therapy (PDT) treatment of cancer.

\section{Mechanisms of Photodynamic Therapy}

There are two main PDT mechanisms, which occur in tumor cells, in the presence of molecular oxygen (Figure 2). Upon irradiation of a PS with a wavelength of light coinciding its absorption spectrum, the PS molecule becomes converted from a ground state to a singlet excited state [20]. The PS drug loses a part of its energy through fluorescence and the remainder is transferred and so the singlet state PS becomes excited to a triplet state. In a type I mechanism, the triplet excited state PS interacts with biomolecules from tumors surroundings to form radicals, which react with molecular oxygen to produce ROS, such as hydrogen peroxides, superoxide anion radicals, and hydroxyl radicals [20]. In the type II mechanism, the energy from an excited triple state PS is directly transferred to triplet state oxygen $\left({ }^{3} \mathrm{O}_{2}\right)$ to form singlet oxygen $\left({ }^{1} \mathrm{O}_{2}\right)$ (Figure 2A) [20]. Both ROS and ${ }^{1} \mathrm{O}_{2}$ induce cancer tumor cell death via either apoptotic, necrotic, or autophagy cell death pathways, depending on the intracellular localization of a PS [21]. Apoptotic cell death is usually due to mitochondrial PS localization and damage, whereas necrotic cell death is mostly due to cell membrane damage and loss of integrity. Within autophagy cell death, usually the PS induces endoplasmic reticulum or lysosomes damage; however, this form of PDT induced tumor cell death is not favored since cells can recover [21]. 
A

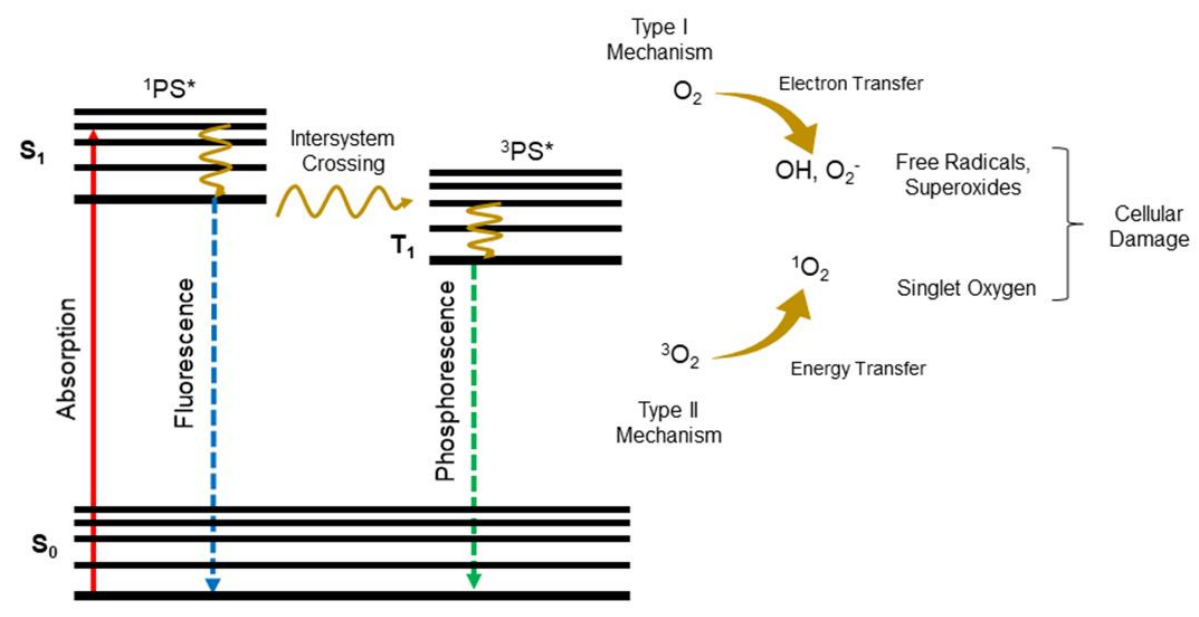

B

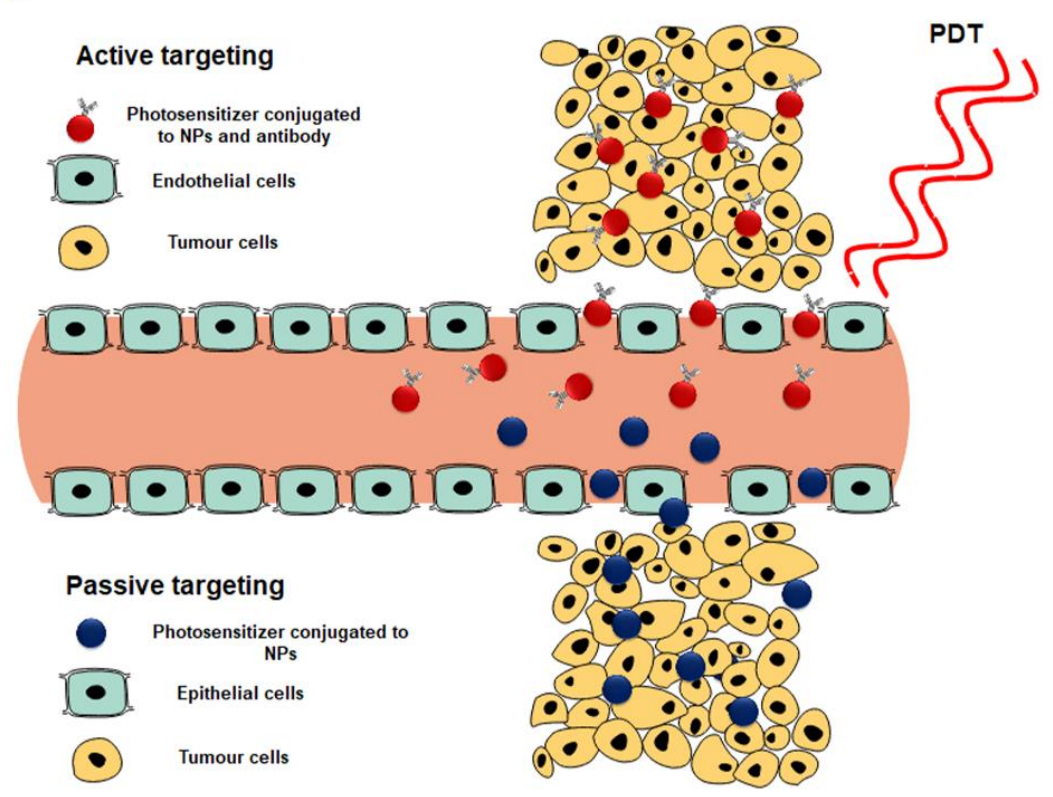

Figure 2. (A) PDT mechanism of action, as well as (B) passive and active tumor photosensitizer (PS) targeting approaches to generate reactive oxygen species (ROS) and singlet oxygen for tumor destruction (PS* indicates an excited state photosensitizer).

\section{Passive and Active Targeting PS Uptake Strategies}

PS subcellular localization uptake can be classified into either passive or specifically active targeting (Figure 2B). Passive PS uptake is encouraged via the permeability and retention (EPR) effect, which causes tumor tissues to present a leaky vasculature [22]. It is natural occurring process, which utilizes the difference in anatomical and pathophysiological abnormalities of cancer tissue versus normal cells to improve PS passivation in tumor cells [22]. When nanoparticle carriers are bound to PS, they tend to promote the passive uptake of PSs via the EPR effect [22]. Active targeting requires the binding of specific targeting ligands, such as antibodies, peptides, aptamers, folic acid (FA), small ligands, or carbohydrates, onto the surface of PS-loaded nanocarrier systems, which are explicitly overexpressed only on cancer cell receptors; thus, PS uptake in these cells is specifically enhanced and actively internalized [22].

In comparison to passive targeting, nanoparticle active targeting most definitely does provide a more selective absorption of PS in tumor cells with improved PS concentration 
accumulation; thus, higher accumulation of the nanocarrier and cellular concentration of the drug into the cells will take place $[22,23]$.

\section{Nanoparticle Delivery Systems for PDT}

Drug delivery systems based on nanoparticles (NPs) are a promising approach in PDT to enhance PS absorption in cancer cells. A large surface to volume ratio of the NPs can promote the loading capacity of PSs and so improves concentration delivery and either passive or active uptake in cancer cells [24]. In addition, anchoring of PSs to NPs can improve either the stability and solubility, as well as reduce dark toxicity and enhance localized delivery, to improve PDT treatment outcomes and minimize unwanted side effects [24]. Moreover, the small size of NPs, not only assists PSs to accumulate in cancer cells via passive or active targeting, but also allows these nanocarrier to mimic biological molecules and, thus, easily pass through immune system barriers [25]. In relation to active targeting, PS nanocarriers are usually further functionalized with specific ligands, which are compatible to overexpressed tumor sites, to improve their biocompatibility and specific targeted absorption [26].

Various organic and inorganic NP carrier platforms have been developed over the years for improved PS uptake and enhanced PDT treatment of BC. In this current review, the utilization of actively targeted inorganic NPs for PDT of BC has been discussed over 10 years.

\section{Types of Inorganic NPs Utilized for Active Breast Cancer Targeting PDT Treatments}

Inorganic NPs have great advantages over organic nanomaterials through their high stability, tunable size, and optical properties, as well as ease of surface functionalization to make them more biocompatible within biological applications [27,28]. Additionally, metallic and inorganic NPs have a lower degradation rate when compared to organic NPs [29]. The main characteristics of inorganic NPs have been summarized in Table 1.

\subsection{Noble Metal Nanoparticles}

Among various types of metallic NPs, gold NPs are ideal candidates for PS delivery into the body, due to their inertness, low toxicity, and limited side effects, as well as ease of synthesis and surface functionalization [30]. Furthermore, gold NPs are able to enhance the passive uptake of a PS-carrier system in tumor cells via the EPR effect [30,31]. Moreover, gold NPs possess a large surface area, which can be functionalized with a variety of ligands for active targeting [32]. Considering the high binding affinity of gold to thiol and amine groups, these NPs can be easily functionalized with antibodies, proteins, nucleic acids, and carbohydrates, which enable selective targeting and enhanced PS delivery in cancer tissues [33]. 
Table 1. Main properties and structures of inorganic nanoparticles (NPs).

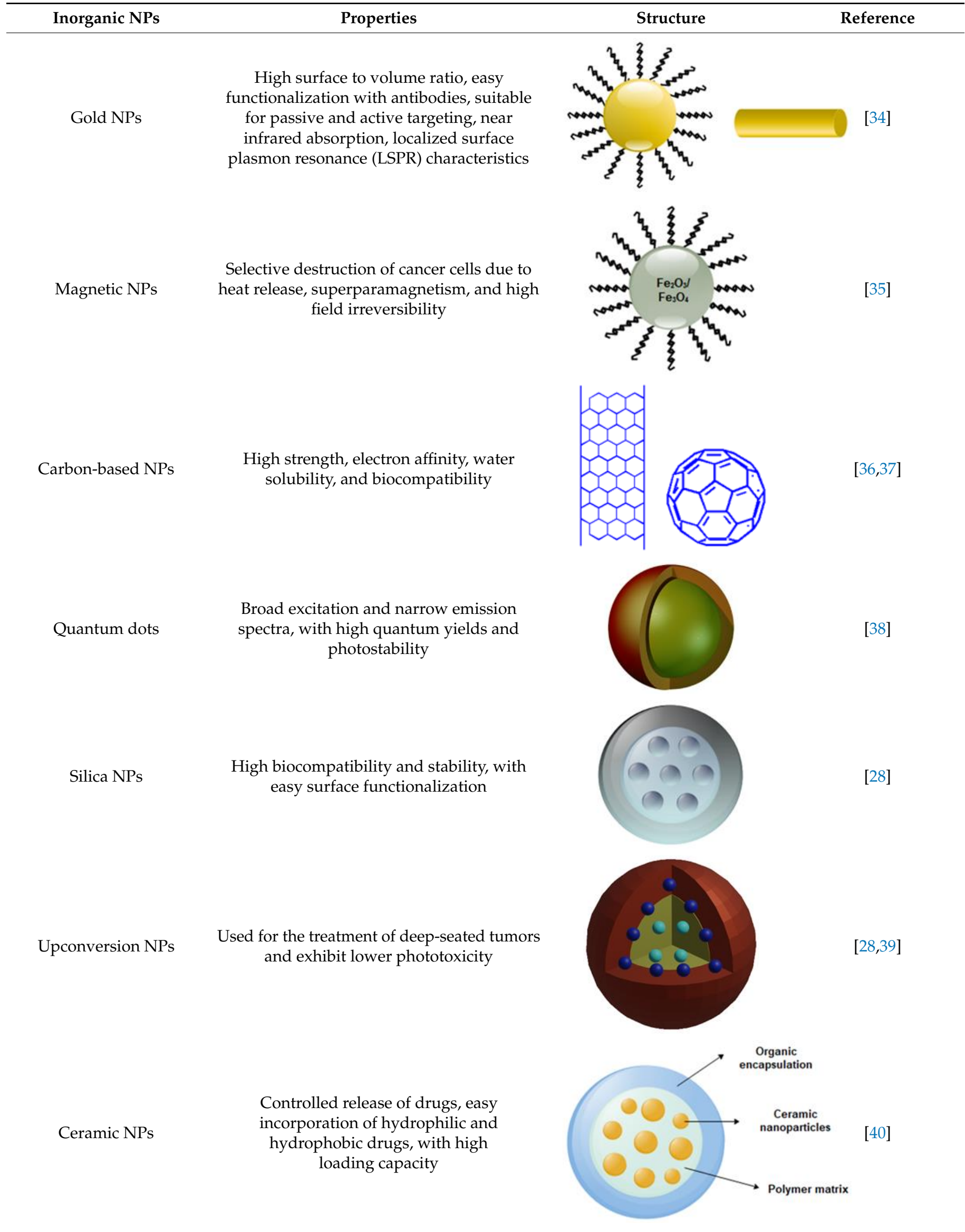


Gold NPs can be employed for imaging contrast agents and radiosensitizers thanks to the high atomic number of gold [30]. Furthermore, since gold NPs have a high atomic number and optical properties of light absorbance within near infrared (NIR) wavelengths [14], they generate heat when exposed to NIR laser irradiation, through surface plasmon resonance effects, allowing them to induce hyperthermia in tumor cells and so assist in improving PDT treatment outcomes [30]. In addition, since gold NPs peak absorbance wavelength is within the visible range of $400-600 \mathrm{~nm}$, NIR light is transmitted through normal cells with low absorption [41], resulting in hyperthermia induction in cancer cells, with very little damage to surrounding healthy cells [42]. Lastly, the surface plasmon resonance effect of gold NPs within the NIR region enhances singlet oxygen and ROS generation [28], and so they tend to improve the overall treatment effect of PDT [31].

Studies by Li et al. (2009) noted that the passive tumor uptake of gold PS nanoconjugates in BC cells could be enhanced by binding them to active targeting biomarkers [43]. With respect to active targeting, a novel 4-component anti HER-2 antibodyzinc-phthalocyanine derivative-polyethylene glycol-gold NP conjugates were prepared for the in vitro PDT treatment of SK-BR-3 (BC cells with HER-2 receptors), MDA-MB-231 (BC cells without the receptor overexpression), and normal breast cells (MCF-10A) [44]. The study noted that the binding of the antibody to the gold PS nanoconjugate did not have an effect on the rate of singlet oxygen production and fluorescence microscopy demonstrated higher BC cellular uptake in SK-BR-3 cells, due to active HER-2 receptor targeting [44]. Within PDT treatments using $633 \mathrm{~nm}$ laser irradiation, the gold PS antibody nanoconjugate induced $40 \%$ cell death in SK-BR-3 cells, whereas MDA-MB-231 only noted $25 \%$, and normal MCF-10A reported 7\% cell death [44]. These findings suggested that active antibody receptor targeting enhanced the delivery of the PS in BC, which has over expressed HER-2 receptors, and so significantly improved the overall treatment outcomes of PDT [44].

In a similar study, gold NPs were stabilized with hydrophobic zinc phthalocyanine PS (C11Pc) and hydrophilic polyethylene glycol (PEG) for the PDT treatment of SK-BR-3 BC [45]. The C11Pc-PEG gold NPs were then further functionalized with jacalin (a lectin specific for cancer-associated Thomsen-Friedenreich (T) carbohydrate antigen) or with monoclonal antibodies specific for the human epidermal growth factor receptor-2 (HER2) [45]. The study revealed that the NP conjugates were more specifically internalized within the acidic organelles SK-BR-3 BC cells [45]. Within PDT treatments under $633 \mathrm{~nm}$ irradiation, both jacalin and antibody conjugates at $\mathrm{C} 11 \mathrm{Pc}$ equivalent concentrations of $1 \mu \mathrm{M}$ and $1.15 \mu \mathrm{M}$, showed 99\% cell death [45]. However, antibody-conjugates note the main advantages of limited PS dark toxicity, when compared to the jacalin-conjugates in SK-BR-3 BC cells, since prior to irradiation, antibody-conjugates reported a 58.9-70.2\% viability, whereas jacalin-conjugates noted $85.5-98.5 \%$ [45].

Relating to the PDT effect of zinc phthalocyanine PSs on BC cells, gold NPs were functionalized with two substituted zinc (II) phthalocyanine PSs, with differing carbon chain lengths (C3Pc or $\mathrm{C} 11 \mathrm{Pc})$, a lactose derivative for stabilization, and a BC galectin-1 targeting agent [32]. Theses functionalized NPs-PSs were utilized to evaluate in vitro PDT efficiency of two breast adenocarcinoma cell lines namely, SK-BR-3 and MDA-MB-231 [32]. The conducted studies showed that the galectin-1 receptors overexpressed on the surface of MDA-MB-231 cells could only be targeted via the lactose-C3Pc-AuNPs, whereas the lactose-C11Pc-AuNPs in SK-BR-3 cells reported no active galectin-1 targeting. Furthermore, post-PDT (at $633 \mathrm{~nm}$ ) no internalization and cell death was observed in MDA-MB-231 cells treated with lactose-C11Pc-AuNPs. Whereas, the lactose-C3Pc-AuNPs reported significant galectin-1 receptor targeting in both $\mathrm{BC}$ cell lines and noted far higher cytotoxicity in comparison to the C11Pc PS [32].

The PDT effect of gold NPs prepared via biphasic and monophasic approaches on SK-BR-3 in vitro cultured human BC cells was further elaborated by Penon et al. (2017) [46]. The gold NPs were further functionalized with a porphyrin derivative and PEG (PRAuNP-PEG) synthesized using two different protocols [46]. The monophasic method reported more porphyrin derivative attached ligands per NP and higher singlet oxygen 
species yields than when compared to the biphasic nanoconjugates [46]. The researchers then covalently linked an anti-erbB2 antibody (PR-AuNP-PEG-Ab) to the monophasic PR-AuNP-PEG nanoconjugates, to target the overexpressed erbB2 receptors on the surface of SK-BR-3 BC cells [46]. Overall, the study noted higher cellular PR PS targeted uptake in BC cells when compared to normal cells, suggesting it had solubilized the PS, with significant cellular damage after $495 \mathrm{~nm}$ laser irradiation PDT treatment [46].

In other studies, gold nanostars have showed promising characteristics for Raman diagnostics. Since gold nanostars have tunable plasmon bands in the NIR tissue optical window, as well as multiple sharp branches, these act as "hot-spots" and so are capable of the surface-enhanced Raman scattering (SERS) effect [47]. Inspired by the unique SERS properties of gold nanostars, Fales et al. (2013) proposed the utilization of these nanostars for the Raman imaging and PDT treatment of BT-549 BC cells [48]. The nanotheranostic system comprised of a Raman-labelled gold nanostar, protoporphyrin IX (PpIX) PS, and a cell-penetrating peptide (CPP) known as transactivator of transcription (TAT) to enhance PS intercellular accumulation of the nanoplatform [48]. The gold nanostars were also coated with PEG and silica shells to enhance particle stability and PS-loading capacity [48]. Raman imaging results noted that the nanoplatform actively accumulated in the BC cells, due to the overexpression presence of TAT peptides [47]. The PDT treatment of BT-549 BC cells with $0.1 \mathrm{nM}$ nanoconjugate and $633 \mathrm{~nm}$ irradiation revealed a higher photocytotoxicity and cell death, when compared to the $0.1 \mathrm{nM}$ PpIX-loaded NP platforms without TAT [48].

The application of gold nanomaterials has been further developed to gold nanorod applications for successful BC active targeting PDT treatments. The enhanced active uptake of gold nanorods within in vitro cultured MCF-7 BC cells was found when gold nanorods were conjugated with anti-HER-2 antibodies [49]. Dube et al. (2018) reported that the conjugation of a complex of glycosylated zinc phthalocyanine to gold nanorods (AuNRs) could improve triplet, singlet, and fluorescence quantum yields, more than gold nanospheres (AuNSs), in PDT applications [50]. PDT results at $680 \mathrm{~nm}$ noted that less than $50 \%$ viable MCF-7cells were found at a concentration of $\geq 40 \mu \mathrm{g} / \mathrm{mL}$ complexAuNRs, while this same result was only achievable at a concentration of $\geq 80 \mu \mathrm{g} / \mathrm{mL}$ complex-AuNSs, suggesting that AuNRs improve PS uptake and PDT outcomes at far lower concentrations [50].

A nanoplatform of AuNR@MSN-RLA/CS(DMA)-PEG was also proposed for the combinational PDT/photothermal therapy (PTT) of MCF-7 breast cancer [51]. Gold nanorods were coated with mesoporous silica (AuNR@MSN) and $\beta$-cyclodextrin $(\beta-C D)$, as well as loaded with Indocyanine green (ICG) [51]. The nanoplatform was then grafted with an Ada modified RLA peptide ([RLARLAR $]_{2}$ ), to enhance plasma membrane permeability and mitochondria-targeting capacity to form AuNR@MSN-ICG- $\beta$-CD/Ada-RLA [51]. Then 2,3-dimethylmaleic anhydride (DMA)-modified chitosan oligosaccharide-block-poly (ethylene glycol) polymer (CS(DMA)-PEG) was coated onto the surface of AuNR@MSNICG- $\beta$-CD/Ada-RLA to serve as a charge-switchable and anti-fouling layer (Figure 3) [51]. Within in vitro MCF-7 BC cytotoxicity assays, the nanoconjugate showed no obvious toxicity prior to laser irradiation [51]. MCF-7 cells treated with AuNR@MSN-ICG- $\beta$ $\mathrm{CD} /$ Ada-RLA/CS(DMA)-PEG at $\mathrm{pH} 6.8$ displayed a higher inhibition and cellular uptake when compared to AuNR@MSN-ICG, suggesting that CS(DMA)-PEG coating protected the nanoplatform from hydrolysis, and so promoted cancer cell uptake [51]. Moreover, the weak acidity microenvironment of cancer cells could reverse the charge of the AuNR@MSNICG- $\beta$-CD/Ada-RLA/CS(DMA)-PEG nanoplatform, promoting mitochondrial targeting and overall improved ROS generation [51]. When MCF-7 BC cells were treated with the nanoconjugate and $808 \mathrm{~nm}$ NIR laser irradiation, the AuNR@MSN-ICG- $\beta$-CD/AdaRLA/CS(DMA)-PEG complex noted the highest PDT and PTT inhibition relative to control groups, due to its overall stability and superior ROS, which was mediated by the plasmonic photothermal effects and local electric field of the DMA AuNR [51]. In vivo investigations within xenograft nude mouse models noted a higher tumor temperature in mice treated with AuNR@MSN-ICG- $\beta$-CD/Ada-RLA/CS(DMA)-PEG than when compared to those 
treated with AuNR@MSN-ICG, suggesting the DMA coated nanoconjugates were far more superior at treating BS in combination with PDT and PTT therapy [51].

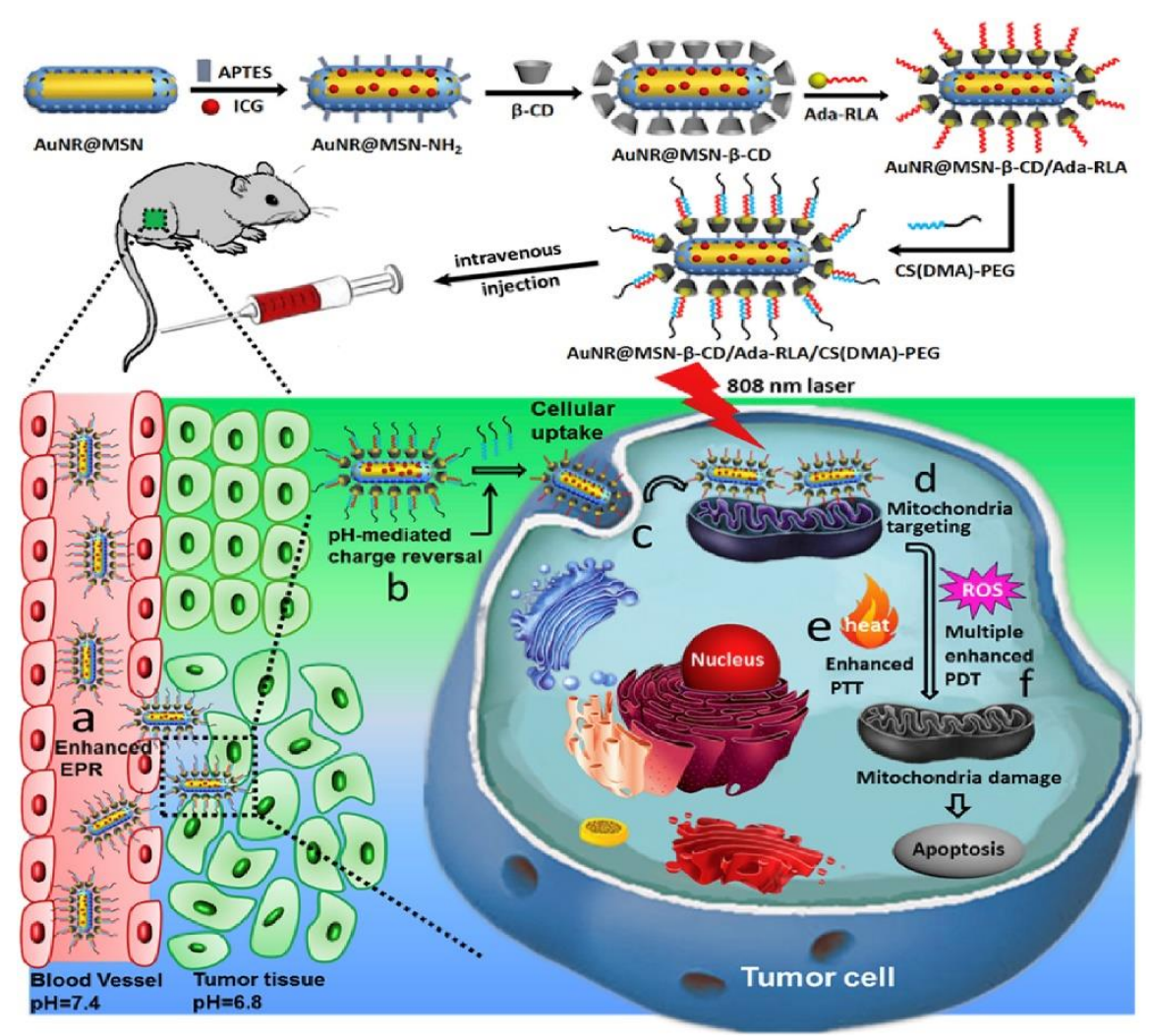

Figure 3. Schematic representation of multifunctional nanoplatform AuNR@MSN and its in vivo process. Reprinted with permission from reference [51] Copyright 2018 Elsevier.

A chlorine e6 PS based (Ce6)-AuNR@SiO 2 -d-CPP nanoconjugate template was developed by synthesizing gold nanorods and passivating PEGylated mesoporous $\mathrm{SiO}_{2}$ onto the gold NPs surface core to entrap the Ce6 PS [52]. Then, a D-type cell penetrating peptide (d-CPP) was linked to the gold nano shell to direct active PS targeting of the nanocarrier towards human BC MCF-7 cells [52]. Free Ce6, $\mathrm{AuNR} @ \mathrm{SiO}_{2}-\mathrm{mPEG}$, and Ce6-AuNR@SiO ${ }_{2}-$ $\mathrm{d}-\mathrm{CPP}$ showed no dark cytotoxicity within in vitro cultured $\mathrm{BC}$ cells. The combinative PDT $(650 \mathrm{~nm}) / \mathrm{PTT}(808 \mathrm{~nm})$ therapy results on BC cultured cells noted that Ce6-AuNR@SiO ${ }_{2}$-dCPP provided the highest treatment outcomes and caused almost complete cell death [52]. The injection of Ce6-AuNR@SiO ${ }_{2}-\mathrm{d}-\mathrm{CPP}$ into a nude mouse BC xenografts and exposure to PTT/PDT combinational therapy noted a significant decrease in tumor weight sizes [52].

Dendrimer-encapsulated NPs (DENs) were first reported in 1998, whereby metal ions were encapsulated within dendrimers, and to reduce them to produce zerovalent DENs [37]. DENs are synthetic polar macromolecules consisting of branches that emanate from a core that has functional groups of neutral, positive, or negative charges [53]. They are monodisperse NPs, which have lower toxicity in cells, a high surface reactivity, as well as allow for slow release and, thus, report a great accumulation in tumor cells, making them suitable for various drug delivery enhancement applications [54]. Poly(propyleneimine) (PPI) and poly(amidoamine) (PAMAM) dendrimers are some examples of DENs [55].

In this regard, one study evaluated the applicability of multiple particles delivery complexes (MPDC) for the PDT treatment of MCF-7 BC cell, using $680 \mathrm{~nm}$ laser irradiation [56]. The MPDC was comprised of gold NP encapsulated dendrimers (AuDENPs) and a sulfonated zinc-phthalocyanine mix (ZnPcs mix) [56]. The morphology of the PDT AuDENPs-ZnPcs ${ }_{\text {mix }}$ treated BC cells noted an altered appearance from epithelial-like to irregular and a $59 \%$ of apoptotic cell death was found, in comparison to control groups [56]. 
In addition, a decrease in the polarized mitochondrial membranes of the BC cells and an increase in the depolarized cell membranes were observed after PDT treatment, with an increase in caspase $3 / 7$ activity and cytotoxicity being found [56].

Recently, a multi-stimuli-responsive theranostic nanoplatform for the fluorescence imaging-guided PDT/PTT dual-therapy of MCF-7 BC cells was proposed [57]. The nanoplatform was based on functionalizing AuNRs with hyaluronic acid (HA), and subsequently conjugating anti-HER-2 antibody, 5-aminolevulinic acid (ALA) and Cy7.5 onto the HA, to enhance active PDT targeting and fluorescence imaging respectively (Figure 4) [57]. Cellular uptake efficiency of AuNR-HA-ALA/Cy7.5-HER-2 noted a significantly improved uptake of 75.5\% in MCF-7 cells when compared to control groups, which received AuNR$\mathrm{HA}^{\text {-ALA } / C y 7.5}$ of $36 \%$, suggesting the nanoplatform improved PS uptake via the specific HER-2 receptor mediated dual-targeting strategy [57]. Furthermore, AuNR-HA-ALA/Cy7.5 HER-2 single treated PDT MCF-7 cells at $635 \mathrm{~nm}$ reported a $75.6 \%$ decrease in cell viability, and cells treated with singular PTT at $808 \mathrm{~nm}$ noted a $58.4 \%$ decrease in cell viability [57]. Overall, a combinative PDT/PTT modality at a $5.5 \mu \mathrm{g} / \mathrm{mL}$ ALA concentration with the AuNR-HA ${ }^{\text {-ALA } / C y 7.5}$-HER-2 nanoplatform noted a significant $61.2 \%$ cell death [57]. Within in vivo studies on BC-induced mice, this dual treatment modality showed a rapid decrease in tumor sizes 20-days post treatment [57].

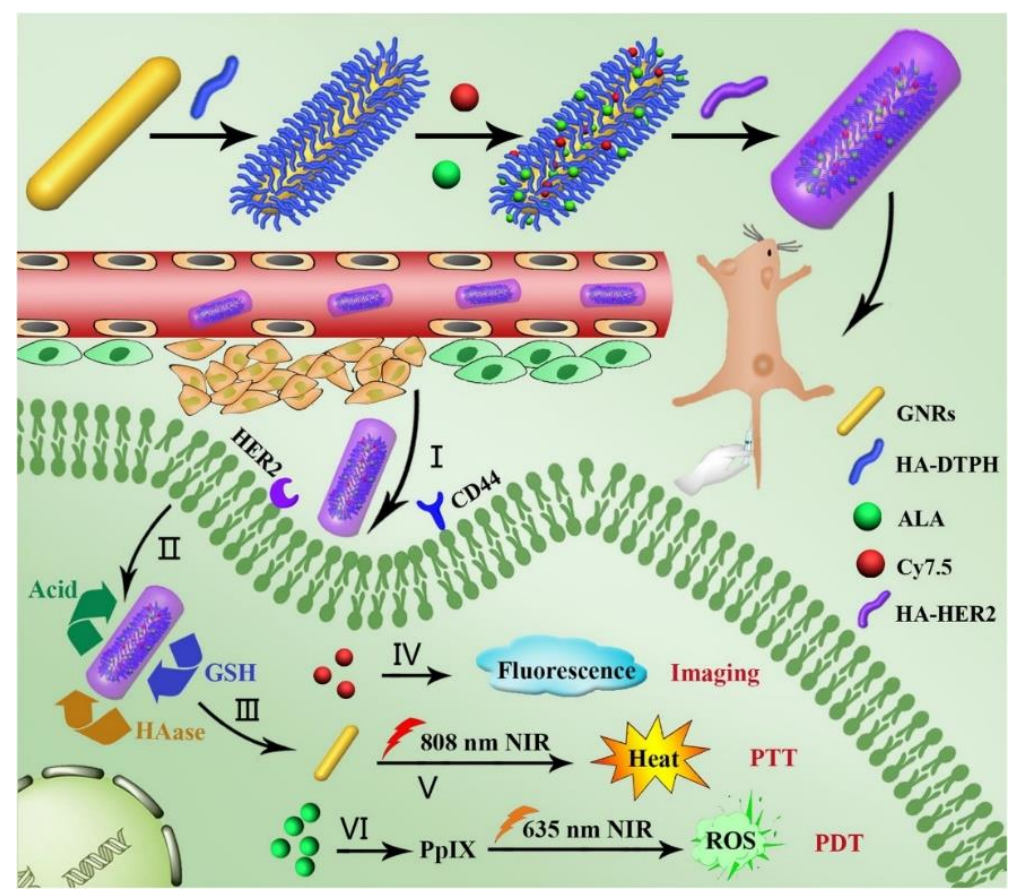

Figure 4. Schematic illustration for preparing GNR-HA ${ }^{-A L A} /$ Cy7.5-HER2 with triple-responsive drug release and its application for HER2/CD44 dual-targeted and fluorescence imaging-guided combined PDT/ photothermal therapy (PTT) treatment of breast cancer. Reprinted with permission from reference [57]. Copyright 2019 Elsevier.

NP drug carriers are sometimes easily recognized and cleared from the body via the mononuclear-phagocyte system (MPS); thus, the surface of NPs drug carriers are generally coated with PEG to act as a shield, and so reduce this biological clearance [58]. However, some studies have noted that upon second administration of PEGylated NP drug carriers the human body can sometimes become stimulated to produce anti-PEG antibodies, resulting in the unwanted rapid clearance of the PEGylated NP, decreasing overall drug uptake in tumor cells [58-60]. In order to alleviate the rapid clearance of NPs via MPS, researchers have focused on red blood cells (RBCs), since they are a natural long-circulation delivery vehicle, which do not interfere or impact on the functionality of NPs [61-63]. 
In a study, cationized gold nanoclusters (CAuNCs) with various initial sizes of 150, 200, and 300 nm were constructed and coated with HA (CAuNCs@HA) [58]. In order to increase the circulation of the CAuNCs@HA nanoclusters, an RBC membrane was attached to its surface forming mCAuNCs@HA [58]. The mCAuNCs@HA nanoclusters were then loaded with a pheophorbide A (PheoA) PS, which is a ROS-responsive prodrug paclitaxel dimer (PXTK) and an anti-PD-L1 peptide dPPA forming pPP-mCAuNCs@HA [58]. This combinative PDT, chemotherapy and immunotherapy treatment approach was investigated within in vitro cultured 4T1 BC cells [58]. The study confirmed that the RBC membrane improved the overall PS in vitro cellular uptake in $4 \mathrm{~T} 1$ cells, which was found to be a 2.02-, 1.55-, and 1.95-fold higher uptake for NP-300, NP-200, and NP-150 nm pPPmCAuNCs@HA, respectively, when compared to uncoated groups [58]. The study also demonstrated that the $650 \mathrm{~nm}$ laser irradiation PDT induced late apoptosis with pPPmCAuNCs@HA was a 2.41-fold higher than when compared to pPP-mCAuNCs@HA without irradiation [58]. The anti-tumor therapeutic effects within in vivo $4 \mathrm{~T} 1$ tumor bearing female mice treated with pPP-mCAuNCs@HA and irradiation was 2.47-fold higher than when compared to groups injected with pPPmCAuNCs@HA without irradiation [58].

The successful applications of gold NPs in BC PDT active targeting treatments within in vitro and in vivo studies have led to more clinical applications [64]. In spite of the fact that gold NPs are inert for bio-tissues and are an alternative platform for PS delivery in PDT BC treatment studies, particular care must be exercised within clinical studies to noted their long-term toxicity and biodistribution, as some tend to have a limited clearance in the spleen and liver; however, this phenomenon is highly dependent on the different shape, size, and surface charge of AuNP [64].

\subsection{Magnetic Nanoparticles}

Magnetic NPs (MNPs) have drawn tremendous attention within in vivo and in vitro biomedical uses, because of their high field irreversibility, small size, and surface functionality $[35,65]$. Within in vitro studies, MNPs have been employed in magnetorelaxometry, diagnostic separation, and selection applications, whilst within therapeutic studies they have been utilized to induce hyperthermia and promote active drug-targeting, as well as assist in diagnostic applications, such as nuclear magnetic resonance imaging (NMR) [66].

Narsireddy et al. (2014) fabricated chitosan coated $\mathrm{Fe}_{3} \mathrm{O}_{4} \mathrm{NPs}$, which were deposited with gold NPs followed by lipoic acid conjugation [67]. A 5,10,15,20-tetrakis(4hydroxyphenyl)-21H,23H-porphyrin PS was also attached onto the surface of gold NPs to form $\mathrm{Fe}_{3} \mathrm{O}_{4}$-Au-LA-PS (MGPS) [67]. In order to improve targeting of this nanoconjugate, human epidermal growth factor receptor specific peptide (Affibody HER-2) was anchored onto its chitosan coat forming Aff-MGPS [67]. The PDT effects of Aff-MGPS were then investigate within in vitro cultured SK-OV-3 BC cells, which are HER-2 positive [67]. The cellular uptake efficiency of the targeted Aff-MGPS was far more superior than when compared to free PS or NPs controls alone (Figure 5) [67]. In addition, no dark toxicity was observed for MGPS or Aff-MGPS nanoplatforms, while free PS noted high dark toxicity [67]. Furthermore, the Aff-MGPS nanoplatforms noted improved targeted peptide uptake in BC cells when compared to group controls [67]. The targeted PDT specific delivery of Aff-MGPS was further assessed in nude SK-OV-3 BC induced tumor mice, in comparison to MGPS treatment alone at $120 \mathrm{~J} / \mathrm{cm}^{2}$, and tumor volumes in mice grew slower in Aff-MGPS PDT treated mice than when compared to MGPS irradiation treatment alone, suggesting Affibody HER-2 enhanced BC PDT targeted treatment outcomes [67].

The photodynamic anticancer activities of magnetic $\mathrm{Fe}_{3} \mathrm{O}_{4} \mathrm{NPs}$ on $\mathrm{BC}$ was further investigated through the conjugation of $\mathrm{Ce} 6$ and FA onto its surface to form $\mathrm{Fe}_{3} \mathrm{O}_{4}$-Ce6FA [68]. The synthesized nanoconjugate could effectively produce ${ }^{1} \mathrm{O}_{2}$ and ROS, with no dark toxicity being found [68]. Within PDT $\mathrm{Fe}_{3} \mathrm{O}_{4}$-Ce6-FA $660 \mathrm{~nm}$ experiments, MCF-7 in vitro $B C$ cells reported a concentration-dependent manner decrease in viability, and increased apoptotic cell death pathway activation via caspase $3 / 7$, with notable nuclear fragmentation and plasma membrane translocation [68]. 

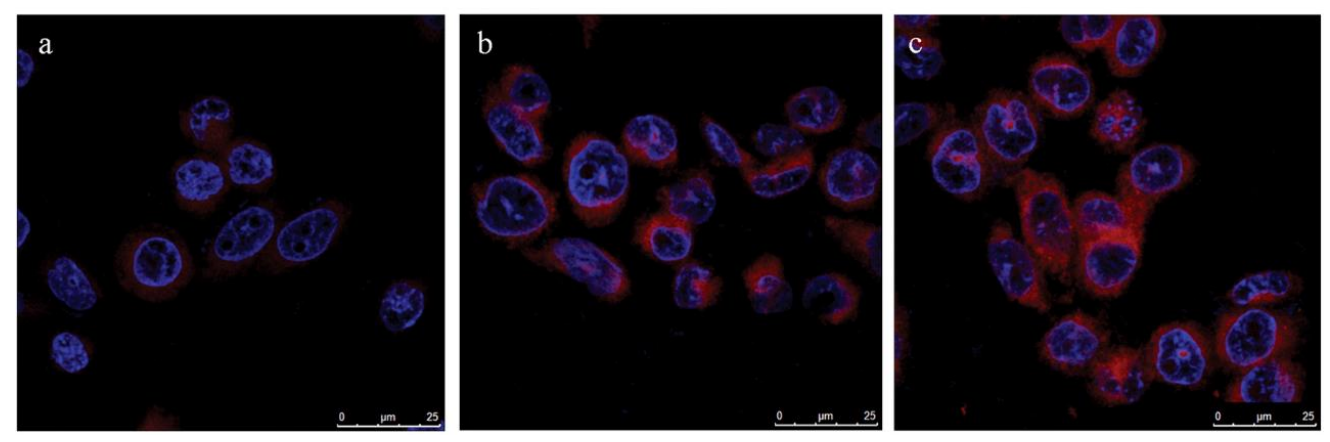

Figure 5. Cellular uptake of (a) free PS, (b) $\mathrm{Fe}_{3} \mathrm{O}_{4}$-Au-LA-PS (MGPS) and (c) Affibody -MGPS.by SK-OV-3 cells. Reprinted with permission from reference [67]. Copyright 2014 Elsevier.

Within a study conducted by Matlou et al. (2018) the aim was to assess the PDT activity of two zinc phthalocyanine $(\mathrm{Pc})$ derivatives: $\mathrm{Zn}$ mono cinnamic acid phthalocyanine and zinc mono carboxyphenoxy phthalocyanine complexes, which were covalently linked to a FA targeting agent and an amino functionalized $\mathrm{Fe}_{2} \mathrm{O}_{3} \mathrm{MNP}$ (AMNPs) [69]. The dark toxicity of this MNP PS carrier noted a significant decrease after attachment of the FA complex [69]. The in vitro MCF-7 PDT effect of Pc-AMNPs noted a significant $60 \%$ cell death under $670 \mathrm{~nm}$ irradiation, when compared to Pc-FA, which only reported a $40 \%$ cell death [69].

$\mathrm{Fe}_{3} \mathrm{O}_{4}$ and $\mathrm{Fe}_{2} \mathrm{O}_{3}$ NPs are supermagnetic [70], and so release a significant amount of heat upon external exposure to laser irradiation and, thus, these NPs are highly effective in combinative PTT and PDT applications to destroy cancer cells [71]. Furthermore, when these magnetic NPs are PEGylating or bound to other polymers, their rapid clearance from the MPS can be alleviated [72]. However, PDT applications with MNPs cannot be taken lightly, as free $\mathrm{Fe}^{2+}$ may react with oxygen or hydrogen peroxide to form $\mathrm{Fe}^{3+}$ and hydroxyl radicals, which are toxic and can damage DNA; thus, the confirmation of the stability of these NP as PS carriers is crucial [70].

Even though only a few studies have been performed using MNPs for the active PDT treatment of BC, their superparamagnetic PTT hyperthermia properties have been demonstrated as a powerful and efficient approach in clinical trials of unresectable tumors or cancers representing terminal illness [73]. Furthermore, MNPs can be utilized in multiple therapeutic and diagnostic strategies [73], as well as eradicating apoptosis resistant cancer cells, since they generate heat intracellularly within the lysosomes and the tumor stroma, and so can obliterate tumor cells completely via necrotic cell death [74,75]. Thus, further studies and investigations utilizing MNPs for the effective treatment of BC is an ongoing need.

\subsection{Carbon-Based Nanoparticles}

Fullerene, carbon nanotubes, and graphene are carbon nanomaterials, which are commonly utilized as PS nanocarriers in PDT applications [76-78]. When PSs are attached via covalent or non-covalent bonding to functionalized carbon-based nanomaterials, they often provide improved solubility and biocompatibility in PDT treatments [36]. Fullerenes are carbon-based nanomaterials, which present in the forms of tubes, ellipsoids, or spheres, and successfully produce ROS upon irradiation exposure at an appropriate wavelength [28]. Single walled or multi-walled carbon nanotubes are other types of PS nanocarriers used in PDT cancer treatments [28]. Since carbon nanotubes present advantageous characteristics, such as fast elimination, low cytotoxicity, ease of functionalization, and reliable internalization through endocytosis, it makes them ideal PS nanocarriers in PDT [28]. Regarding graphene nanomaterials, due to their large surface areas they offer high therapeutic loading capacities for enhanced PS uptake in tumor cells [79].

In studies performed by Shi et al. (2014), fullerene-iron oxide NPs (IONP) were synthesized and functionalized with PEG, Ce6, and FA (C60-IONP-PEG-FA) for the active 
tumor targeting [80]. The performance of these multifunctional NPs was studied for their PDT effect, radiofrequency thermal therapy (RTT), and magnetic targeting, within in vitro MCF-7 BC cells and in vivo BC mice models [80]. Individual in vitro PDT assays at concentration of $16 \mu \mathrm{g} / \mathrm{mL}$ C60-IONP-PEG-FA and $532 \mathrm{~nm}$ laser irradiation, 31.3\% viability was reported, and individual RTT therapy at the same concentration with $13.56 \mathrm{MHz}$ radiofrequency noted a 36.9\% of viable cells [80]. In combinational C60-IONP-PEG-FA RTT, followed by PDT, in vitro assays reported a significant $18.8 \%$ of cells only being found to be viable [80]. Within in vivo studies on S180 BC tumor-bearing mice, individual PDT and PTT applications induced $62 \%$ and $37 \%$ of apoptosis, respectively, and the integration both treatments could enhance apoptotic cell death to 96\% [80].

By taking advantage of the ultra-high loading capacity of graphene oxide (GO) through $\pi-\pi$ stacking and hydrophobic interactions [81], GO(HPPH)-PEG-HK was prepared by functionalizing it with PEG-GO, so that a HK peptide (which binds specifically to integrin $\alpha v \beta 6$ on BC tumors) could be linked to it [82]. This actively functionalized nanoconjugate was then coated with a Photochlor (2-[1-hexyloxyethyl]-2-devinyl pyropheophorbidealpha, HPPH) PS [83]. The large surface area of GO enabled conjugation of multiple $\mathrm{HK}$ peptides and high concentrations of $\mathrm{HPPH}$, allowing for improved in vivo PDT treatment outcomes of BC [83]. Within in vivo 4T1 BC tumor mouse models, results reported that GO(HPPH)-PEG-HK under $671 \mathrm{~nm}$ laser irradiation that tumor growths remarkably decreased in comparison to control groups [83]. Furthermore, studies went on to note that remarkable increases in the $\mathrm{CD} 40^{+}$and $\mathrm{CD}^{+}{ }^{+}$fractions in treated mice after PDT treatment with GO(HPPH)-PEG-HK induced dendritic cell maturation and so promoted anti-tumor immunity in the 4T1 tumor model (Figure 6) [83]. Thus, this actively functionalized nanoconjugate via PDT application could reduce in vivo BC tumor sizes, as well as trigger host anti-tumor immunity, to cause the inhibition of metastasis and further tumor growth [83].
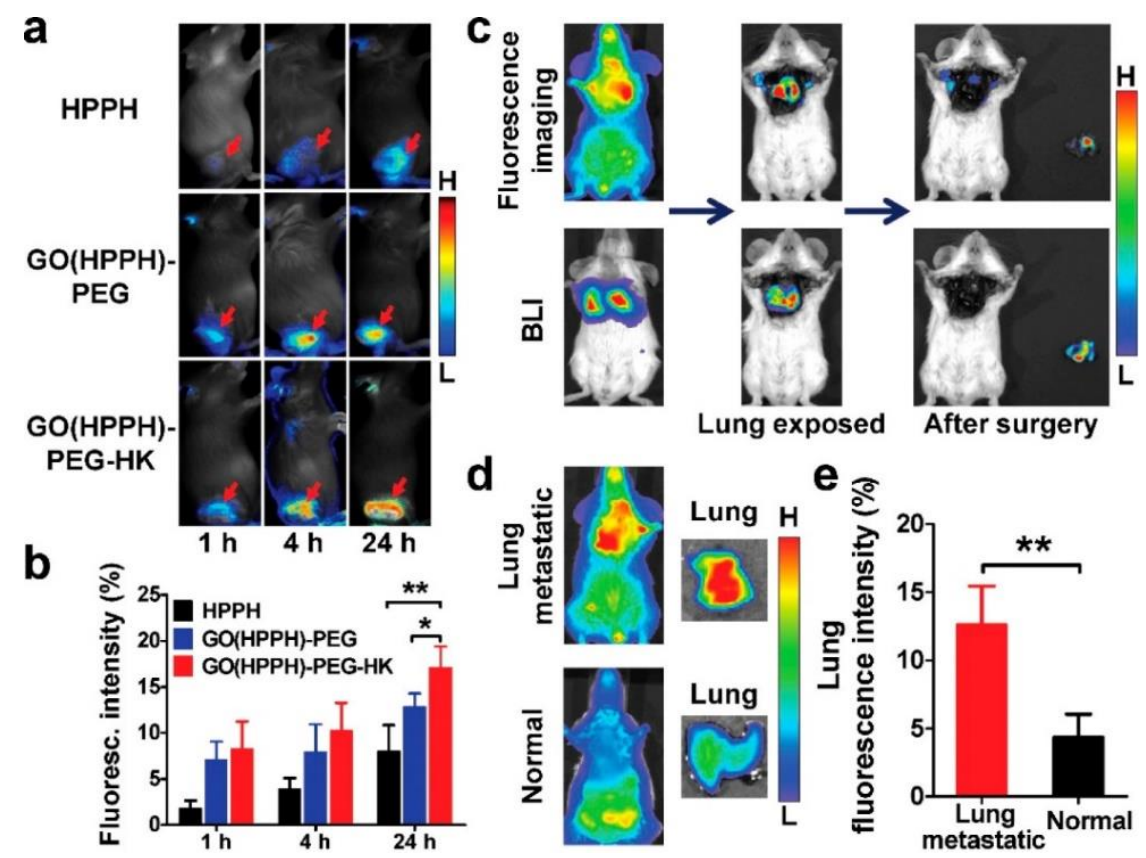

Figure 6. (a) Optical images of $4 \mathrm{~T} 1$ tumor-bearing BALB/c mice, (b) quantitative analysis uptake by 4T1 tumors after injection of HPPH, GO(HPPH)-PEG, or GO(HPPH)-PEG-HK, (c) In vivo optical imaging and BLI of 4T1-fLuc tumor-bearing BALB/c mice after injection of GO(HPPH)-PEG-HK. (d,e) Optical images and quantitative analysis of lung uptake of GO(HPPH)-PEG-HK by 4T1-fLuc tumor-bearing and normal BALB/c mice at $24 \mathrm{~h}$ post-injection. Reprinted with permission from reference [83]. Copyright 2017 American Chemical Society. ${ }^{*} p<0.05,{ }^{* *} p<0.01$. 
Overall, very few studies have been conducted using carbon-based nanomaterials for the active PDT targeting of BC. However, from the above studies, it can be seen that the combination of the synergistic effects of carbon-based NPs with PSs can improve the efficacy of BC PDT treatment [76]. It is worth mentioning that fullerene cages, such as C60 [84] and carbon nanotubes [85], can act alone as PSs in PDT applications and so self-generate ROS from photons owing to their $\pi$ bond electrons [86]. Thus, fullerene derivatives alone are competitive PSs for in vivo PDT or preclinical treatment [87], since no additional PS is required to generate ROS and, thus, should be researched further for BC treatment [76]. Despite all of the idealistic properties carbon nanotubes have, they sometimes can induce asbestos-like inflammation [73], which is a carcinogenic, and so their individual toxicity needs to be fully investigated and understood [88].

\subsection{Semiconductor Quantum Dots (QDs)}

Quantum dots are a subclass of fluorescent nanomaterials, which have unique chemical and physical properties compared to organic dyes [89]. They have been utilized as multifunctional nanocarriers for PDT thanks to their high quantum yields, simple surface modification, and tunable optical properties [90]. They are also excellent donors in fluorescence resonance energy transfer (FRET) applications [91]. To date, no studies have been investigated relating to the application of active targeted QDs for the PDT treatment of BC.

Studies by Monroe et al. (2019) only performed a spectrophotometric assay in order to assess the cellular uptake, cytotoxicity, and ROS generation of graphene QDs (GQDs) associated with methylene blue (MB) PS against in vitro cultured MCF-7 BC cells [92]. This study reported that $\mathrm{MB}$ improved cytotoxicity and ROS generation when compared to a 1:1 GQD:MB ratio [92].

In another study, $\mathrm{Zn}$ (II) phthalocyanines (ZnPcs) with different substitutes were fabricated and conjugated to GQDs to investigate the in vitro PDT activity of Pc-GQDs conjugates in a human BC in vitro MCF-7 cell line [93]. The conjugate and Pcs alone did not report dark toxicity and in vitro PDT studies noted that Pc-GQDs conjugates enhanced treatment outcomes when compared to Pcs administration alone [93].

The above QD-based BC PDT studies have paved a new avenue for researchers to synthesize various targeted-QDs against breast cancer. It has been reported that QDs have potential cytotoxicity under UV irradiation to act as efficient PSs [90]. Furthermore, NIR fluorescent QDs provide improved PS water solubility, chemical stability, and low optical interference with biological tissues in PDT cancer treatments, when compared to small molecule-based PSs administered alone [94]. Additionally, the large surface area of QDs also enables the conjugation of multiple PSs and ligands for targeted photodynamic imaging [90]. Nevertheless, one of the most controversial problems with QD-based PDT is the high toxicity they possess, since most consist of toxic heavy metals, such as cadmium ions, and so they tend to be under investigated $[90,95]$. In order to alleviate some of these issues cadmium free QDs, such as zinc and indium based QDs [96], substituted with other elements, such as silicon or carbon [97], or their incorporation into polymeric NPs [98] have been proposed to enhance their application in diagnostic applications and PDT cancer clinical trials [99]. Overall, it is envisaged that QDs, particularly GQDs, will open the door to a multitude of new opportunities for PDT treatment of BC, and through continued research, they could subsequently be able to provide high biocompatibility and improved PS solubility in biological media, with less unwanted toxic effects.

\subsection{Ceramic Nanoparticles}

Ceramics NPs are inorganic solids made up oxides, carbides, carbonates, and phosphates, and have properties that range between metals and non-metals [40]. Silica $\left(\mathrm{SiO}_{2}\right)$, titanium oxide $\left(\mathrm{TiO}_{2}\right)$, alumina $\left(\mathrm{Al}_{2} \mathrm{O}_{3}\right)$, zirconia $\left(\mathrm{ZrO}_{2}\right)$, calcium carbonate $\left(\mathrm{CaCO}_{3}\right)$, and hydroxyapatite (HA) are some examples of ceramic NPs with porous characteristics that can be fabricated to control the release of drugs [40]. The main features of ceramic NPs are high loading capacity, stability, and chemical inertness, as well as heat resistance and 
ease of conjugation to either hydrophilic or hydrophobic drugs [29], making them highly advantageous for drug delivery, imaging, photodegradation of dyes, and photocatalysis applications $[37,40,100]$.

\subsubsection{Silica Nanoparticles}

Silica is an oxide of silicon and one of the most efficient materials for controlled drug delivery, since it can store and be controlled to gradually release therapeutic drugs [40]. Mesoporous silica nanoparticles (MSNs) are formed by polymerizing silica, and so have distinctive properties, such as tunable pore size (allowing for a high therapeutic drug loading capacity capacities) [101], large surface area to volumes, automatic release of drugs, as well as ease of functionalization with various functional groups or ligands, offering actively targeted drug delivery capabilities [40]. Thus, within PDT applications, PSs can be easily covalently linked or encapsulated onto the surface of silica NPs for favorable cancer treatment outcomes [28].

A nanosystem comprised of mesoporous silica NPs (MSN) with covalent anchoring of a synthesized anionic porphyrin PS and BC targeting mannose was presented by Brevet et al. (2009) [102]. The study confirmed that PS mannose-functionalized NPs within in vitro cultured MDA-MB-231 BC cells improved the efficiency of PDT relative to the non-functionalized NPs, since it induced 99\% cell death when irradiated at 630-680 nm with $6 \mathrm{~mW} / \mathrm{cm}^{2}$, while non irradiated control groups only noted 19\% cell death [102].

Another promising nanoconjugate PS depended on a two-photon absorption, which integrated a two-photon excitation (TPE) with silica nanotechnology $[103,104]$. Conventional PSs require the absorption of a single photon equal to the band-gap energy of a PSs [105]. However, when a PS absorbs two lower energy photons of infrared light, TPE can occur and the sum of the photon energies are equal to the band-gap of energy, leading to a deeper light penetration and lower photo-bleaching of the actual PS [105-109]. Furthermore, in a TPE, the nonlinearity of photon absorption allows a PS activation to occur at the focal point of a laser beam, and so allows for greater spatial control of PS activation in three-dimensional (3D) tumor models, decreasing off-target phototoxicity in surrounding healthy tissues [110,111].

With respect to the TPE-PDT, a porphyrin functionalized porous silica NP (pSiNP) was coupled to a mannose targeting moiety to investigate the imaging and PDT potentials within in vitro cultured MCF-7 BC cells [112]. When compared to other two-photon absorbing nanoparticles such as, CdSe quantum dots, gold nanorods, or carbon dots, pSiNPs appear to be biodegradable in vivo [113], since their silicon components degrade to silicic acid, which can quickly be eliminated by kidneys [112,113]. The authors of this showed that the pSiNP with mannose moieties were able to actively accumulate in MCF-7 BC cells, with far higher PDT efficacy, since phototoxicity results noted a 2.3-fold better outcome for two photon PDT at $800 \mathrm{~nm}$ than when compared to one-photon excitation at $650 \mathrm{~nm}$ [112].

Within studies performed by Cao et al. (2014), in order to enhance PS accumulation in BC cells, it was proposed to use mesenchymal stem cells (MSCs) to directly deliver a PS to in vitro cultured MCF-7 cells [114]. The application of MSCs in PDT cancer treatments seems promising, as various studies have demonstrated that they have a naturally high tumor affinity within in vivo tumors, they can be easily isolated from bone marrow and modified to carry desired drugs, as well as be efficiently implanted into patients to avoid immune system clearance [115-118]. In this study, porous hollow silica NPs were conjugated to a purpurin-18 PS ( $\left.\mathrm{PS}-\mathrm{SiO}_{2} \mathrm{NPs}\right)$ and then they were loaded into the MSCs cells ( $\mathrm{PS}-\mathrm{SiO}_{2} \mathrm{NPs}-\mathrm{MSC}$ ) for in vivo PDT studies in MCF-7 modified mouse models (Figure 7a) [114]. Results noted that the BC tumor affinity of the MSCs was not inhibited by loading PS-SiO${ }_{2} \mathrm{NPs}$ into the MSCs, and that intercellular ROS generation proportionally increased with PS-SiO${ }_{2} \mathrm{NPs}-\mathrm{MSC}$ s conjugation upon laser irradiation, suggesting the in vivo $B C$ tumors retained the PS [114]. In addition, within PDT studies, the in vivo groups that received $\mathrm{PS}-\mathrm{SiO}_{2}$ NPs-MSCs reported far greater tumor growth inhibition than 
when compared to control groups, which received unmodified MSCs without loading PS-SiO ${ }_{2} \mathrm{NPs}$, suggesting that the MSCs cells were capable of high PS BC tumor affinity targeting (Figure 7b) [114].

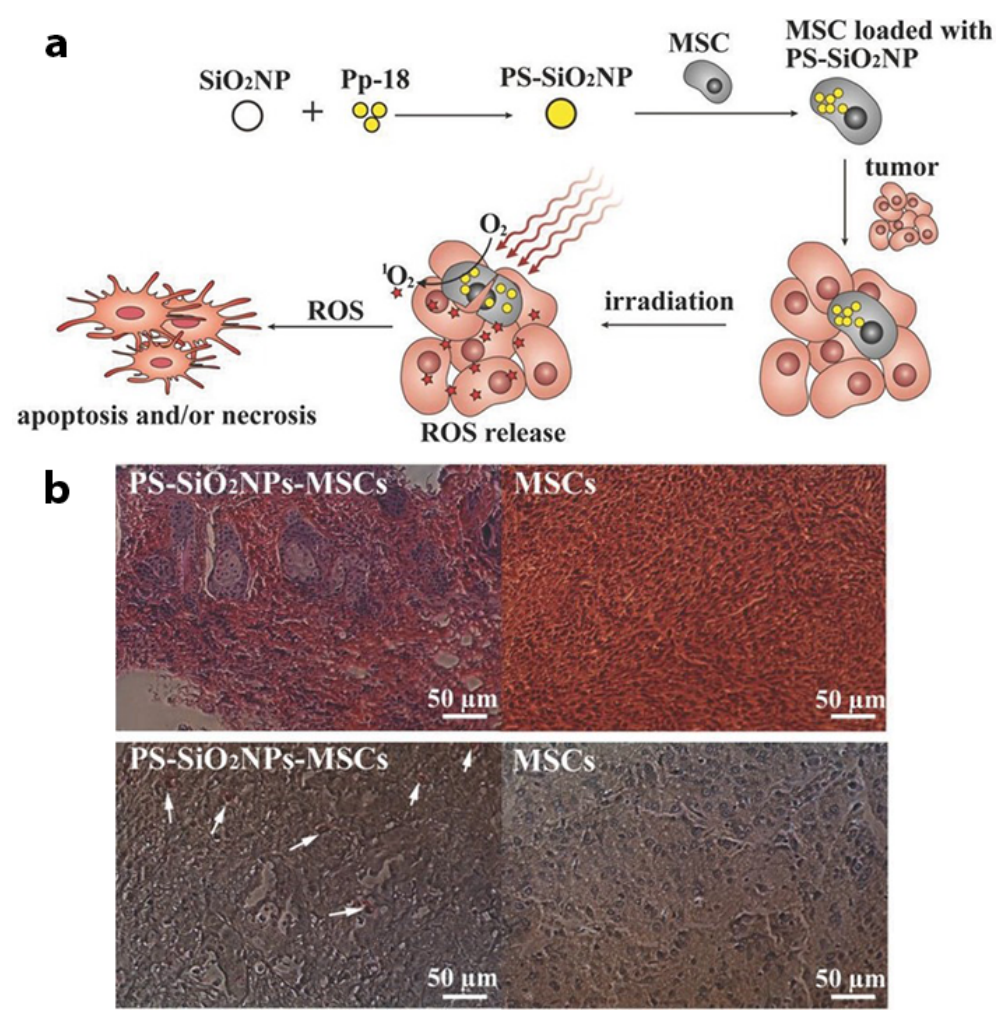

Figure 7. (a) PDT treatment of cancer cell using PS-loaded $\mathrm{SiO}_{2} \mathrm{NPs}$ into MSCs, (b) In vivo PDT treatment on tumors one day after co-injection of MCF-7 cancer cells and MSCs with (group 1: $\mathrm{PS}-\mathrm{SiO}_{2} \mathrm{NPs}-\mathrm{MSC}$ group) or without (group 2: control MSCs group) $\mathrm{PS}-\mathrm{SiO}_{2} \mathrm{NPs}_{\text {loaded. Reprinted }}$ with permission from reference [114]. Copyright 2014 Willey Online Library.

Studies by Bharathiraja et al. (2017) reported that silica NPs decorated with Ce6 and FA (silica-Ce6-FA) could accumulate far higher within in vitro cultured MDA-MB-231 BC cells, when compared to free Ce6 [119]. Even though the level of ROS generated by silicaCe6-FA nanoconjugate was moderately lower than when compared to free $\mathrm{Ce} 6$, at $680 \mathrm{~nm}$ PDT, the study showed that due to the folate receptor targeting in the nanoconjugate, the PS uptake in BC cells was improved, and so higher cell death was observed than when compared to free Ce6 administration alone [119].

Although, NIR light within the range of $630-800 \mathrm{~nm}$ is employed as an excitation PDT source to treat deep-seated cancer tissues [120], most clinically approved PSs have a low absorption in NIR region, and so their overall penetration depth is less than $1 \mathrm{~cm} \mathrm{[121].} \mathrm{Thus,}$ researchers have also begun to investigate $\mathrm{X}$-ray sources for use in X-ray-mediated PDT (X-PDT), since they are able to penetrate far deeper into tissues, which perhaps better outcomes [112]. Within these applications PSs need a system to convert X-rays into UV-visible photons, since they cannot absorb X-ray photons directly [112]. Scintillating nanoparticles or nanoscintillators, such as lanthanide doped rare-earth nanoparticles [122], have emerged as energy transducer for this conversion and deep seated X-PDT treatment [123-125].

Studies by Sengar et al. (2018) investigated X-PDT for the deep penetration of BC tumors [126]. They synthesized $\mathrm{Y}_{2.99} \mathrm{Pr}_{0.01} \mathrm{Al}_{5} \mathrm{O}_{12}$-based (YP) mesoporous silica (MS) coated NPs and functionalized them with PpIX and FA (YPMS@PpIX@FA) for the X-PDT treatment of BC cells with overexpressed folate receptors (Folr 1) [126]. The utilized BC in vitro cell lines were PyMT-R221A mouse BC cells (which have high levels of folate receptors), as well as 4T1 BC cells (which have low folate expression) [126]. PyMT-R221A mouse BC 
cells reported higher cellular uptake of YPMS@PpIX@FA when compared to 4T1 BC cells, revealing that FA targeting of this nanoconjugate was functional [126]. Additionally, nonactivated YPMS@PpIX@FA reported a low cytotoxicity when used at concentrations below $25 \mu \mathrm{g} / \mathrm{ml}$, while upon light activation at $365 \mathrm{~nm}$, a remarkable decrease in PyMT-R221A mouse BC cells was observed [126]. Lastly, administration of YPMS@PpIX@FA suspension at a single dose of up to $125 \mathrm{mg} / \mathrm{kg}$ did not cause the death or any detectable behavior in inoculated CD1 mice [126].

Overall, it can be observed from the above in vitro and in vivo studies that silica NPs seem very promising for the PDT treatment of BC, and due to their non-toxicity and rapid renal clearance, the move forward of these studies into clinical applications is pertinent.

\subsubsection{Titanium Oxide Nanoparticles}

Titanium dioxide $\left(\mathrm{TiO}_{2}\right)$, also called titania, is another type of ceramic NP, which possesses chemical and biological inertness, photostability, photoactivity, and high stability within biomedical applications [127]. More importantly, the strong oxidizing and reducing ability $\mathrm{TiO}_{2}$ has when photoexcited with irradiation at $<390 \mathrm{~nm}$ can produce ROS, which consequently induces apoptotic cell death in BC cells [128].

Studies by Gangopadhyay et al. (2015), constructed $\mathrm{TiO}_{2}$ NPs and decorated them with a 7,8-dihydroxy coumarin PS chromophore and chlorambucil (Ti-DBMC-Cmbl NPs) and FA (Ti-FA-DBMC-Cmbl NPs) to serve as a chemotherapeutic drug and phototrigger, respectfully in PDT/chemotherapy treatments of in vitro cultured MDA-MB BC cells (Figure 8) [129]. After $60 \mathrm{~min}$ of PDT laser irradiation at $\geq 410 \mathrm{~nm}$, cells treated with TiDBMC-Cmbl NPs noted a 35\% cell viability, whereas cell treated with Ti-FA-DBMC-Cmbl NPs reported a mere 19\% cell viability and more significant apoptotic cell death [129]. Overall, results revealed that the synergic effect of both targeted PDT and well known chemotherapeutic drug chlorambucil was successful for the eradication of MDA-MB BC cells [129].

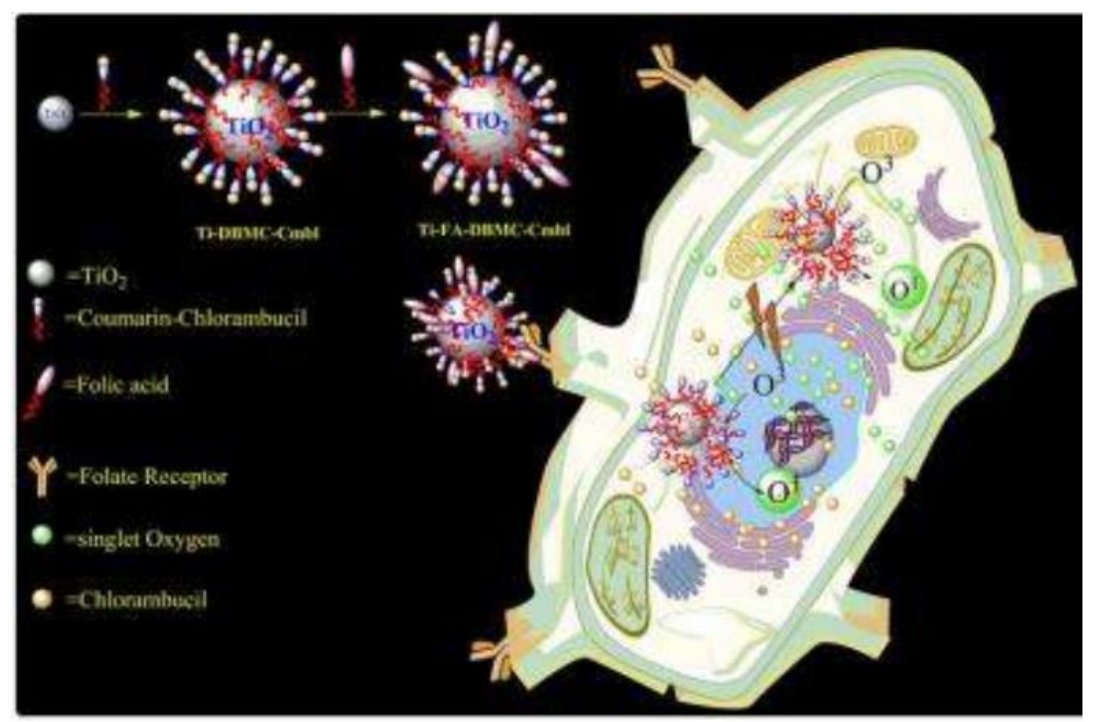

Figure 8. PDT and chemotherapeutic effects of Ti-FA-DBMC-Cmbl NPs on MDA-MB BC cells. Reprinted with permission from reference [129]. Copyright 2015 Royal Chemical Society.

In general, ceramic NPs show great potential in carrying PSs in PDT application to targeted BC tumors, due to their excellent chemical inertness and high heat resistance. However, since limited studies have been performed using ceramic NPs in BC, it is constructive to highlight that a suitable method in relation to their synthesis to control size, porosity, surface area to volume ratio, should be fine-tuned in order to allow for a high PS pay loading capacity and reduce any possible unwanted biological clearance issues [129]. 


\subsection{Other Inorganic Nanoparticles}

Cerium oxide NPs (or nanoceria/ceria NPs) are considered from a lanthanide metal oxide that can be used as an ultraviolet absorber [130]. They have antioxidant properties at a physiological $\mathrm{pH}$, while their oxidases activity in tumors idealistically functions in an acidic microenvironment $[131,132]$. Nanoceria NPs alone tend to have a poor water solubility so they are generally coated with polymers to enhance biocompatibility, stability, and their overall solubility [133].

A multifunctional drug delivery system of PPCNPs-Ce6/FA was introduced by $\mathrm{Li}$ et al. (2016) and it comprised of Ce6/FA-loaded branched polyethylenimine-PEGylation ceria NPs (PPCNPs) for the possible PDT targeting of drug resistant in vitro BC MCF7/ADR cells in combination with chemotherapeutic agent DOX [134]. The results revealed that internalization efficiency and diffusion of the synthesized nanoplatform with positive surface charges via endocytosis in BC cells was far higher than free Ce6 [134]. PDT efficiency under $660 \mathrm{~nm}$ irradiation in BC cells treated with the PPCNPs-Ce6/FA reported a 35\% apoptotic and necrotic cell death, while BC cells treated with PPCNPs-Ce6 only noted an overall 25\% cell death [134]. Moreover, results reported that low-dose PPCNPs-Ce6/FA PDT remarkably improved the chemotoxicity of DOX in in vitro MCF-7/ADR BC cells in a dose-dependent manner [134]. In vivo PDT studies within MCF-7/ADR athymic nude mouse xenograft models showed a significant $96 \%$ reduction in the tumor volume when injected with PPCNPs-Ce6/FA, in comparison to a $25 \%$ reduction when PPCNPs-Ce6 was applied [134].

In relation to metastatic triple-negative $\mathrm{BC}$ ( $\mathrm{mTNBC})$, numerous studies have noted that treatments, such as radiation, cytotoxic chemotherapy, and surgical interventions are ineffective and so this has driven researchers to consider immunotherapy for the possible treatment of mTNBC $[135,136]$. Tumor immunotherapy relies on the fact that BC cells can be eradicated by host cytotoxic CD8 ${ }^{+} \mathrm{T}$ cells $[137,138]$.

In this regard, Duan et al. (2016) introduced a promising strategy using a checkpoint blockade-based immunotherapy for the treatment of primary in vitro 4T1 BC tumors [139]. A non-toxic core-shell comprising of ZnP@pyro NPs was fabricated using Zn and pyrophosphate $(\mathrm{ZnP})$ and a pyrolipid PS was incorporated into its core, for PDT applications, while a PD-L1 antibody was added for checkpoint blockade immunotherapy [139]. Results reported that the immunogenic ZnP@pyro NPs were non-toxic prior to light activation [139]. Within PDT studies, they successfully eliminated in vitro BC cells upon $670 \mathrm{~nm}$ irradiation, through apoptotic and necrotic cell death [139]. PDT in vivo investigations of the ZnP@pyro NPs on orthotopic 4T1 tumor-bearing mice demonstrated that this immunogenic PS nanocarrier enhanced PS uptake via the EPR effect for high tumor accumulation, as well as disrupted tumor vasculature and increased tumor immunogenicity [139]. The authors also claimed that the ZnP@pyro NPs not only prohibited the further metastasis, but also inhibited pre-existing metastatic tumors growth by generating systemic anti-tumor immunity [139].

\subsection{Upconversion Nanoparticles}

The unique "photon upconversion" process of upconversion NPs(UCNPs) has been applied in low tissue penetration depth PDT applications [140,141]. Upconversion is an anti-Stokes shift, which is defined as the conversion of NIR light to a shorter wavelength of light in the visible region [140]. Thus, UCNPs are able to absorb two or more low energy photons and, thus, show a unique anti-Stokes shift of fluorescence emission in UV-Vis wavelengths (300-700 nm) under NIR light excitation (750-1400 nm) [142]. UCNPs can be utilized in biomedical applications as they have shown improved reduced fluorescence background, with lowered phototoxicity [39]. Therefore, in order to treat deep-seated tumors, PSs in NPs are excited with longer wavelength [28] and emitted fluorescence by UCNPs, so can excite PS electrons effectively to produce efficient amounts of singlet oxygen in PDT applications [143]. 
In 1991, Cai et al., utilized novel $\mathrm{TiO}_{2}$ or $\mathrm{ZnO}$ semiconductors, which had photoeffects, such as inorganic PSs for the PDT treatment of cancer [144]. These semiconductors promoted electrons from valance bands to conduction bands upon PDT UV irradiation, leaving electron hole pairs [28] and so resulted in oxidation or reduction of chemical species, such as water and oxygen around the $\mathrm{TiO}_{2}$ or $\mathrm{ZnO}$ semiconductors, to generate ROS [145,146].

In this regard, Janus nanostructures comprised of $\mathrm{NaYF4:Yb/Tm} \mathrm{UCNPs} \mathrm{with} \mathrm{TiO}_{2}$ inorganic PSs were synthesized by Zeng et al. (2015) and loaded with FA and DOX (FA-NPs-DOX) (Figure 9) for NIR-triggered inorganic targeted PDT and chemotherapy treatment of drug-sensitive MCF-7 and drug resistant MCF-7 / ADR BC cells within in vitro and in vivo applications [147]. The chemotherapeutic results alone revealed that the FA-targeted nanocomposite promoted the cellular uptake of DOX, as well as caused a viability decline of $44.4 \%$ in MCF-7 and $28.9 \%$ in MCF-7/ADR BC cells [147]. However, combinational chemotherapy and PDT results under $980 \mathrm{~nm}$ NIR irradiation, noted a far higher significant decrease in cellular viability, whereby only 5.8\% MCF-7 cells were found viable and $17.6 \%$ of MCF-7/ADR BC drug resistant cells were found to alive [147]. Within PDT in vivo assessments on female BALB/c (nu/nu) nude mice, MCF-7 tumor growths reported a $99.34 \%$ inhibition of growth, while MCF-7/ADR tumor growth noted a $96.74 \%$ decline, when treated with FA-NPs-DOX + NIR [147].

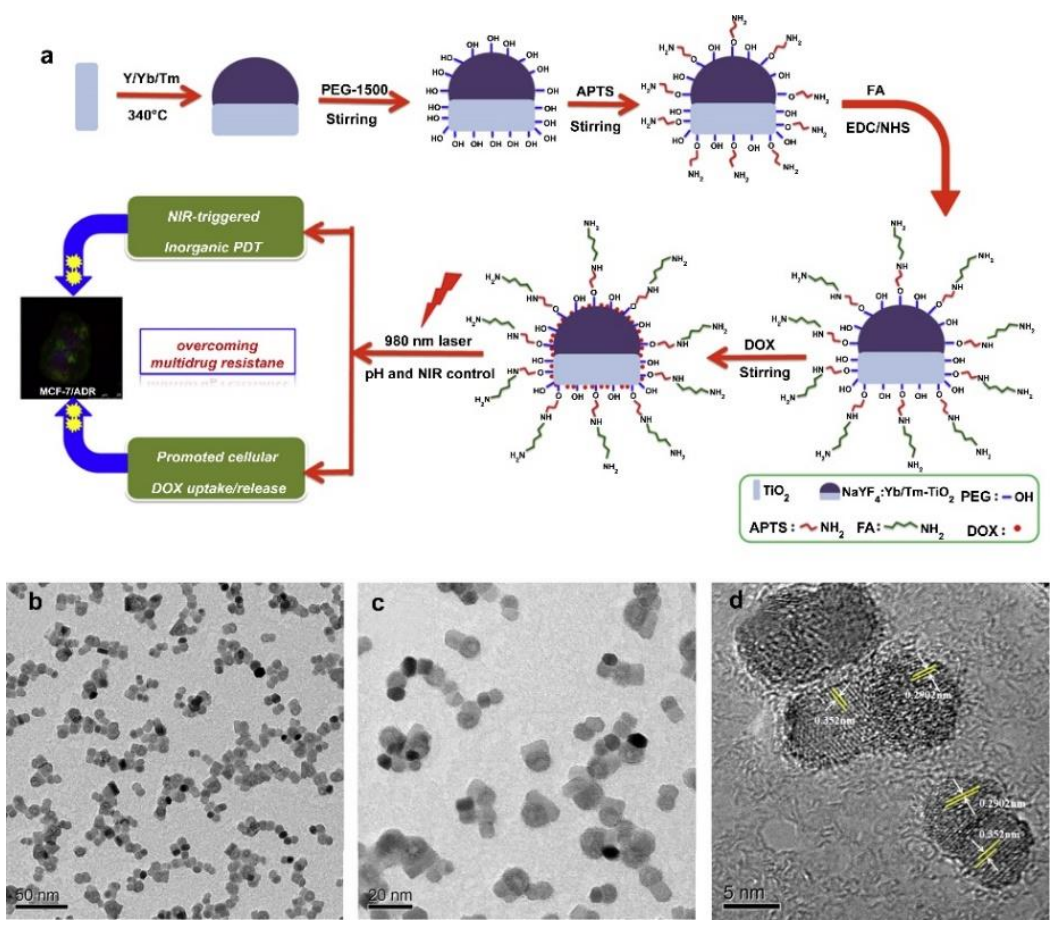

Figure 9. (a) Synthesis of DOX-loaded, FA-targeted NaYF4:Yb/ TmeTiO 2 nanocomposites for NIRtriggered PDT and chemotherapy in resistant breast cancer, (b-d) TEM and HRTEM images of $\mathrm{NaYF4} \mathrm{Yb} / \mathrm{Tm}_{\mathrm{m}} \mathrm{TiO}_{2}$ nanocomposites. Reprinted with permission from reference [147]. Copyright 2015 Elsevier.

In studies by Zeng et al. (2015), HER-2-targeted multifunctional nanoprobes based on 808 nm-excitation bound to NaGdF4:Yb,Er@NaGdF4:Yb@NaGdF4:Yb,Nd UCNPs, with Ce6 PS and $\mathrm{SiO}_{2}$ (T-UCNPs@Ce6@ $\mathrm{mSiO}_{2}$ ) were fabricated for 808 nm irradiation PDT and magnetic resonance imaging (MRI) within in vitro MDA-MB-435 BC cells [143]. Regarding the cellular uptake, the accumulation amount of T-UCNPs@Ce6@mSiO $\mathrm{m}_{2}$ in in vitro BC cells was 1-2 times higher than those treated with UCNPs@Ce6@mSiO ${ }_{2}$, due to HER-2 active targeting [143]. Furthermore, the PDT treatment of in vitro BC cells using nontargeted UCNPs@Ce6@ $\mathrm{mSiO}_{2}$ reported a 16.4\% cell viability, whereas cells treated with 
T-UCNPs@Ce6@mSiO 2 noted a 6.8\% cell viability, suggesting that the PDT efficiency improvement was due to active targeting [143]. Additionally, in vitro T-UCNPs@Ce6@mSiO PDT, reported a significant $16.5 \%$ for early apoptosis and $10.2 \%$ for late apoptosis cell death [143]. The in vivo PDT investigation of nanocomposite in MDA-MB-435 tumorbearing nude mice indicated that the targeted T-UCNPs@Ce6@ $\mathrm{mSiO}_{2}$ significantly enhanced tumor accumulation of up to $12 \%$, whereas the non-targeted UCNPs@Ce6@mSiO only noted a $2 \%$ accumulation potential [143]. Furthermore, the MR signal was far higher and stronger in T-UCNPs@Ce6@ $\mathrm{mSiO}_{2}$ treated mice than when compared to those treated with UCNPs@Ce6@mSiO 2 [143].

Within studies by Wang et al. (2017) Lanthanide-doped UCNPs were encapsulated in fourth-generation poly amido amine (PAMAM) dendrimers, bearing 64 peripheral amines (G4) and Ce6 to assess NIR-trigged PDT in 2D and 3D in vitro MCF-7 BC [142]. The internal cavities within the dendrimers enabled the trapping of small molecules through host-guest affinity and so enhance the cellular uptake of the UCNPs [142]. More importantly, when Ce6 was loaded onto the dendrimer-modified UCNPs, and $660 \mathrm{~nm}$ PDT laser irradiation applied in 2D models 50\% cell death was noted, whereas approximately $70 \%$ cell death was found in those treated with $980 \mathrm{~nm}$ PDT laser irradiation [142]. These findings confirmed that the NIR could pass through the 2D BC tumor cell model membranes and organelles to reach and effectively activate the UCNPs, and so enhance PDT efficacy with deeper tissue penetration [142]. With reference to the 3D model, $980 \mathrm{~nm}$ NIR light noted a deep tumor penetration and produced cell death that was consistent with the 2D model results [142]. Moreover, in vivo PDT assessments using $980 \mathrm{~nm}$ irradiation in 4T1 BC tumor-bearing mouse models treated with high doses of the UCNPs, demonstrated significant tumor growth inhibition, through induction of the $\gamma \mathrm{H} 2 \mathrm{AX}$ ser139 protein marker for DNA double strand breaks; thus, substantial DNA damage was observed [142].

A precise tumor-specific UCNP targeting strategy was assessed by Yu et al. (2018) for the enhanced PDT treatment of in vitro MCF-7 BC cells [148]. NaYF4:Yb ${ }^{3+}, \mathrm{Er}^{3+} \mathrm{UC}-$ NPs capped with polyacrylic acid (UCNPs@PAA) were fabricated and modified with FA and Ce6 PS, as well as were functionalized with DNA sequences of varying lengths (Figure 10A) [148]. The in vitro cellular uptake results showed that the fabricated UCNPs@PAA-DNA located efficiently within BC lysosomes via effective folate receptor targeting (Figure 10B) [148]. Significant reduction within in vitro $980 \mathrm{~nm}$ PDT treated BC cells with UCNPs@PAA-DNA was reported [148]. The study stated that the Ce6 PS on the longer DNA nanocomposite moved to the vicinity of the UCNPs and generated singlet oxygen upon NIR irradiation, through Förster resonance energy transfer (FRET). The study proposed that when the fabricated UCNP reached the BC tumor cells, the $\mathrm{C}$ baserich long DNA within the nanocomposite could form a C-quadruplex and the FA groups overexpressed on the folate receptors of $B C$ cells could be attracted, and so efficiently active $\mathrm{BC}$ tumor targeting was achieved [148]. Furthermore, the pre-protective strategy using UCNPs@PAA-DNA with longer DNA alleviated any other possible side effects on the normal cells, as the FA groups of the shorter DNA was protected by this longer DNA to preclude any possible binding with normal cell folate receptors [148]. In vivo PDT experiments within BALB/c mice with BC xenograft tumors not only demonstrated the successful accumulation of the nanocomposites, but also eliminated tumor volume tenfold in comparison to control groups [148].

Generally, NP particle size can affect their overall uptake and retention in the liver, kidney, and spleen [149], furthermore large sized NPs can induce high toxicity, with unwanted side effects and heightened cellular phagocytosis [150]. Thus, within clinical applications, they tend to be more inclined towards the use of small NPs, which report less retention and unwanted toxicity [151]. Within a study performed by $\mathrm{Yu}$ et al. (2018) a core-multishell nanocomposite (MNPs(MC540)/DSPE-PEG-NPY) was constructed that was an ultrasmall size for the in vitro and in vivo PDT evaluation within MCF-7 BC cells [151]. This UCNP nanostructure was based on a multifunctional $Y_{1}$ Rstargeting ligand [Pro30, Nle31, Bpa32, Leu34]NPY(28-36), abbreviated to NPY and loaded 
with merocyanine 540 (MC540) PS to form LiLuF4:Yb,Er@nLiGdF4@mSiO 2 (MNPs) [151]. Then 1,2-distearoyl-sn-glycero-3-phosphoethanolamine-N-carboxy (polyethylene glycol) 2000] (DSPE-PEG) was coated onto the surface of MNPs to improve water solubility and biocompatibility of the final nanocomposite [151]. Within $980 \mathrm{~nm}$ in vitro PDT assays BC MCF-7 cells treated with MNPs(MC540) noted a 84.8\% cell death, whereas those treated with MNPs(MC540)/DSPE-PEG reported a 86.7\% cell death and those treated with MNPs(MC540)/DSPE-PEG-NPY noted a 93.5\% cell death, suggestive that active targeting and uptake was present (Figure 11) [151]. Within $980 \mathrm{~nm}$ in vivo PDT assays on MCF-7 BC induced female BALB/c nude mice tumor volumes of the groups treated with MNPs(MC540), MNPs(MC540)/DSPE-PEG, and MNPs(MC540)/DSPE-PEG-NPY increased over the first 4 days and then decreased on the sixth day after a double PDT application was performed [151]. After 28 days of a double PDT application, mice injected with MNPs(MC540)/DSPE-PEG-NPY showed no tumor growth [151].
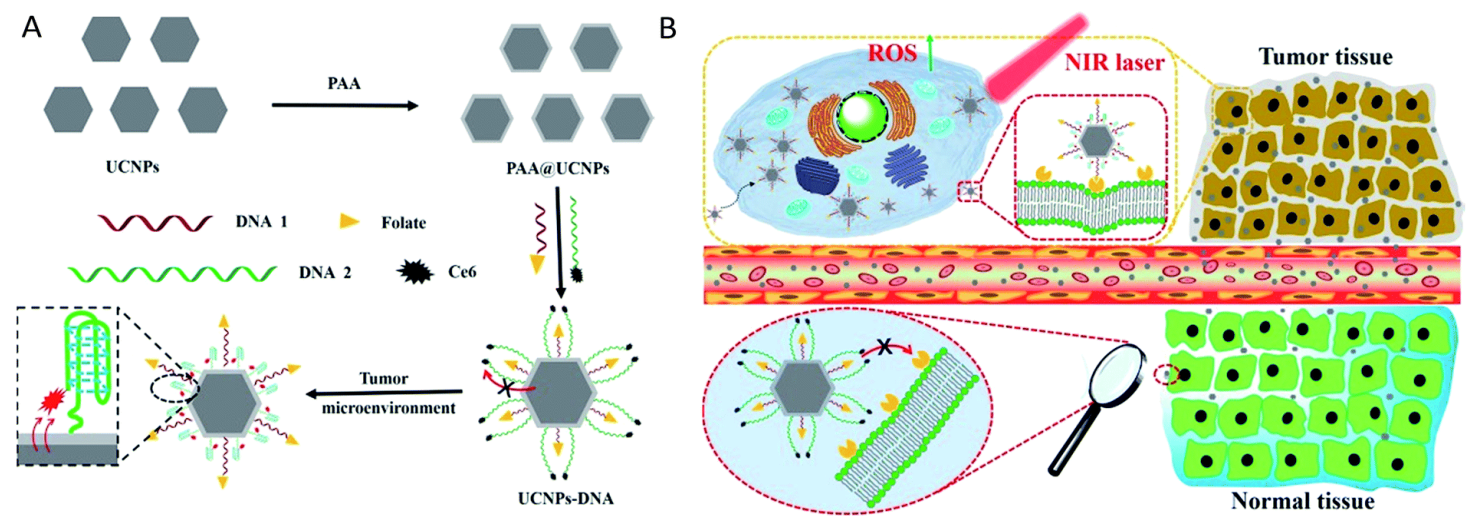

Figure 10. (A) Schematic preparation of UCNPs@PAA-DNA and (B) specific tumor targeting for PDT treatment of MCF-7 cells [148]. Published by The Royal Society of Chemistry (RSC).

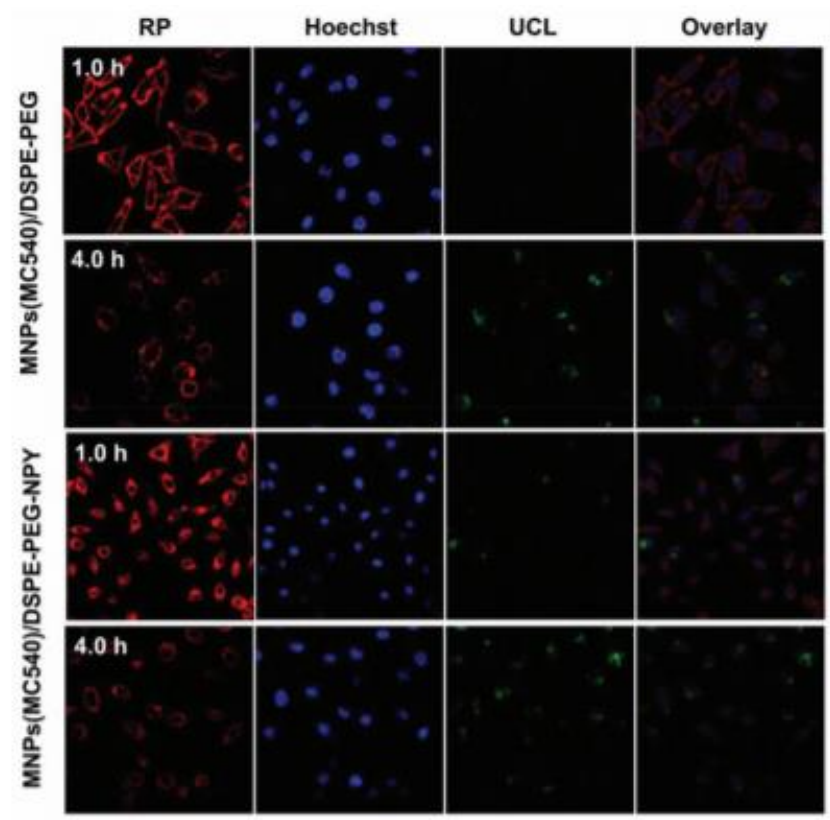

Figure 11. Confocal laser scanning microscopy of MCF-7 incubated with MNPs(MC540)/DSPE-PEGNPY or MNPs(MC540)/DSPE-PEG. Reprinted with permission from reference [151]. Copyright 2018 Royal Chemical Society.

In a study performed by Ramírez-García et al. (2018), a UCNP nanoconjugate was constructed for the targeted PDT and imaging against HER-2-positive BC cells, as well as to try 
and overcome the limited tumor cell depth penetration visible light has [152]. NaYF4:Yb,Er UCNPs were fabricated and attached to a zinc tetracarboxyphenoxy phthalocyanine ( $\mathrm{ZnPc}$ ) PS and a trastuzumab (Tras) HER-2 specific monoclonal antibody to form a UCNPs-ZnPcTras nanocomposite [152]. The covalent bonds between UCNPs and ZnPc resulted in resonance energy transfer from the NPs to the PS, which in turn produced cytotoxic singlet oxygen and higher ${ }^{1} \mathrm{O}_{2}$ quantum yields when compared to control groups [152]. The PDT efficacy of this nanocomposite was evaluated in vitro within HER-2 positive SK-BR-3 and HER-2 negative MCF-7 human BC cells [152]. Cytotoxicity assays post-PDT at $975 \mathrm{~nm}$ noted higher values in HER-2 positive SK-BR-3 BC cells than when compared to HER-2 negative MCF-7 human BC cells, suggestive that enhanced PS targeting uptake was present due to specific HER-2 targeting [152]. Moreover, post-PDT HER-2 positive SK-BR-3 BC cells noted a 93.5\% cell death, when compared to HER-2 negative MCF-7 human BC cells which reported a mere $21.8 \%$ cell death, suggestive that this nanocomposite was capable of specific and far more enhanced HER-2 positive BC receptor mediated targeted PDT [152].

As previously mentioned, photocatalysis $\mathrm{TiO}_{2}$ NPs are nontoxic and have a high photochemical stability to yield improved levels of ROS upon irradiation [153]. When $\mathrm{TiO}_{2}$ NPs are utilized within PDT applications as PS, a far higher and controlled loading with improved uptake has been reported [154]. Furthermore, other studies noted that when doping metal atoms, such as $\mathrm{ZrO}_{2}$, are attached to $\mathrm{TiO}_{2}$ heterostructures, they can temporarily constrain the high recombination rate of photogenerated electron-hole pairs in $\mathrm{TiO}_{2} \mathrm{NPs}$ when electron-hole pairs migrate from the inside of the photocatalyst to the surface, improving PDT treatment outcomes [154,155]. In a more recent study performed by Ramírez-García et al. (2019), a NaYF4:Yb,Tm UCNP core was fabricated and coated with photo-effecting material $\mathrm{TiO}_{2}-\mathrm{ZrO}_{2}$ as a shell to improve NIR-triggered PDT (NaYF4:Yb,Tm@ $\mathrm{TiO}_{2} / \mathrm{ZrO}_{2}$ core@shell NPs) [153]. The monoclonal antibody known as Tras was also added to the UCNPs surface, to improve its overall NP PS active targeting within HER-2 positive in vitro cultured SK-BR-3 human BC cells [153]. Within PDT assays at $975 \mathrm{~nm}$ irradiation at $400 \mu \mathrm{g} / \mathrm{mL}$ the NaYF4: $\mathrm{Yb}, \mathrm{Tm} @ \mathrm{TiO}_{2} / \mathrm{ZrO}_{2}$-tras nanocomposite reported $76 \%$ cell death, whereas control groups treated with single $\mathrm{TiO}_{2} \mathrm{UCNP}$ that lacked $\mathrm{ZrO}_{2}$ attachment, only $40 \%$ cell death was found [153]. Overall, these results revealed that the combinative photocatalytic activity of $\mathrm{TiO}_{2}-\mathrm{ZrO}_{2}$ within the final nanocomposite, improved the PDT treatment outcomes in BC cells due to higher levels of ROS being produced [153].

Studies by Feng et al. (2019) employed a promising strategy called a "all-in-one", whereby imaging and therapeutic PDT functions were integrated into one nanoplatform, by anchoring a PSs to UCNPs to allow for dual imaging-guided PDT within in vitro MCF-7 BC cells [156]. A bioorthogonal chemical reaction was utilized in this study to allow for a "off/on" state of PDT, in order to circumvent any issues associated with photoactivity of preloaded norbornene-rose bengal (RB-NB) PS, since it can produce skin photosensitivity and so damage normal cells [156]. Thus, a NaYF4: Er, Yb@NaYF4 UCNP was synthesized and covalently bound to a pre-targeting tetrazine (Tz) and FA molecule to form a UCNPsTz/FA-PEG (Figure 12a), which was utilized as the one handle of the bioorthogonal reaction in tracking and imaging of deep-seated tumors, since it lacked PS [156]. Then when the RB-NB PS were attached on the surface of the nanoplatform via a bioorthogonal chemical reaction (as the other handle of the UCNP), it demonstrated efficient PS targeting, UCNP energy transfer to the PS, with high yields of ROS and so enhanced treatment within in vitro BC tumors under $980 \mathrm{~nm}$ irradiation (Figure 12b) [156]. Upconversion luminescence (UCL) imaging of the nude mice injected with MCF-7 BC cells showed high accumulation of the nanoplatform in tumor sites, due to FA active targeting and EPR effect [156]. Furthermore, in vivo PDT assays on these tumor bearing mice when treated with NPs-Tz/FA-PEG + RB-NB under $980 \mathrm{~nm}$ irradiation provided $75.5 \%$ decrease in tumor size when compared to control groups [156]. 
a)

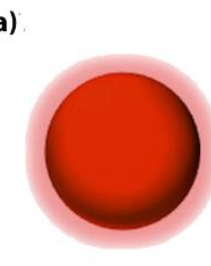

b)
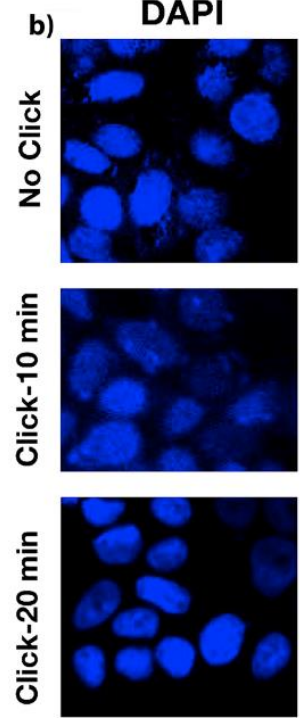
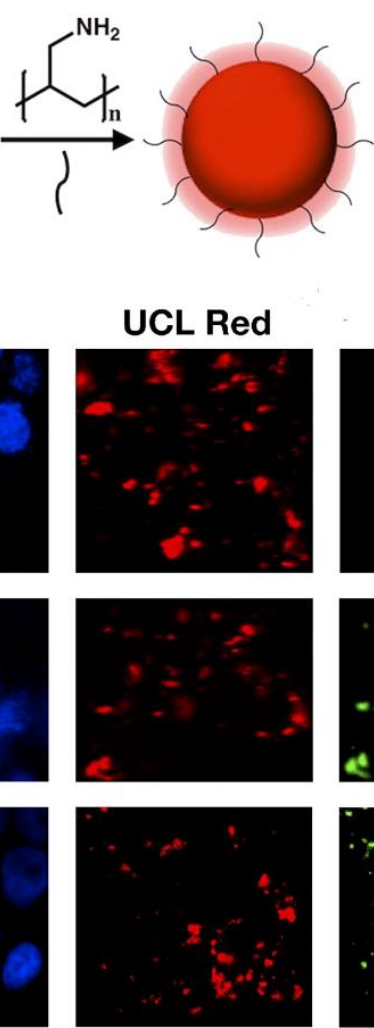

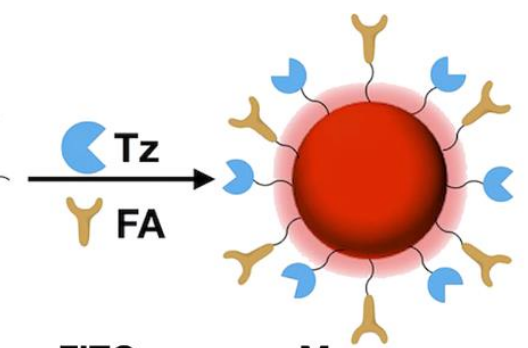

FITC
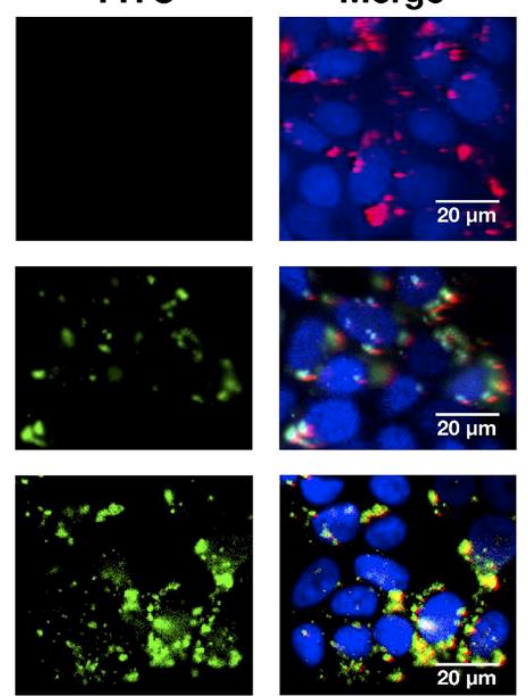

Figure 12. (a) Schematic synthesis of UCNPs-Tz/FA-PEG, (b) MCF-7 cells treated with UCNPsTz/FA-PEG or UCNPs-FA-PEG for UCL imaging with $980 \mathrm{~nm}$ light excitation (red channel), and click reaction with FITC-NB (green channel), and stained with DAPI (blue channel). Top: control (no click), middle: click for $10 \mathrm{~min}$ and bottom: click for $20 \mathrm{~min}$. Reprinted with permission from reference [156]. Copyright 2019 Elsevier.

A lot of research has been carried within the utilization of UCNPs for the enhanced PS delivery and PDT treatment of BC, due to their ability to be allow for PS activation within the higher NIR wavelength ranges, and consequently be able to provide deeper penetration of tumor tissues, when compared to visible light applications, since the upconversion visible emission from UCNPs can excite PS to produce more ROS [140,157]. It is envisaged that the integration of UCNPs with more NIR penetrable light and idealistic PSs will potentiate near-future targeted PDT BC clinical trials.

\section{Conclusions and Perspectives}

$\mathrm{BC}$ is invasive form of cancer, which can metastasize, and frequently recurs after treatment [2]. Many conventional therapies utilized for BC often present themselves with some form of resistance and unwanted side-effects, and surgery is invasive [3]. In this sense, actively targeted PDT is gaining a prominent position as a non-invasive, limited side effect approach for the treatment of BC.

The combination of NPs with PSs, to passively, as well as actively enhance their accumulation in tumor tissues more selectively in order to enhance PDT treatment outcomes, as well as lessen the unwanted side effects on localized tissues is fast becoming a popular approach [22,23].

Inorganic NPs have unique properties, which assist in reducing PS leaching, allow for a high loading capacity of PSs, improve PS passive uptake via the EPR effect, and allow for ease of functionalization with various ligands to promote active PS absorption and, thus, allow for the overall enhancement of PDT BC treatment $[27,158]$. Furthermore, inorganic and metallic PS nanocarriers are less susceptible to degradation and do not release attached 
PSs, but rather allow activated ROS after irradiation to diffuse out of them, when compared to organic NPs, and so are more prominently utilized within the field of PDT $[29,158]$.

Gold NPs for example have shown surface plasmon resonance effects that can intensify singlet oxygen quantum yield, as well as induce hyperthermia promoting the overall effect of PDT [28]. Furthermore, inorganic NPs, such as UCNPs can provide a deeper penetration of light in tumors [140] or porous silica NPs allow for the entrapment of oxygen to improve overall PDT treatment outcomes [28].

Anchoring of active targeting moieties to PS-loaded inorganic NPs, allow nanosystems to be specifically directed towards BC cells only, allowing enhanced PS accumulation, which is localized in tumor target cells, only limiting unwanted side effects on normal cells [22,23]. It is also noteworthy to emphasize that the number of receptors per tumor cell is $10^{5}$, while the number of the PS molecules that can be attached to an inorganic NP to obviate cancer cells is $10^{7}$, allowing each tumor receptor to be able to at least receive a $10^{2} \mathrm{PS}$ concentration [159]. Thus, the binding of targeting ligand to PS-loaded NPs is imperative to ensure the highest uptake possible of PSs in tumor cells, in order to promote PDT treatment outcomes [159].

It is postulated that, in the near future, the applications of nanotechnology to potentiate PDT should allow for the widespread of breast cancer amongst women to be overcome [159]. However, additional comprehensive studies are still required to scrutinize the physiochemical, pharmacokinetic properties, and safety profiles of nanocarriers, so that maximum accumulation and PS uptake can be attained in the target tissues. In addition, although anchoring of the PSs on the surface of NPs can enhance their biocompatibility, the potential toxic effects and unwanted liver and renal accumulation, must be taken into consideration. Thus, it is imperative that the above discussed and reviewed inorganic NP studies for the actively applied targeted PDT treatment of BC in vitro and in vivo be investigated further within clinical trials, so that the possible future targeted PDT treatment of $\mathrm{BC}$ can become a reality.

Supplementary Materials: The following are available online at https:/ / www.mdpi.com/1999-492 3/13/3/296/s1, Table S1: spectroscopic and physicochemical properties of some photosensitizers utilized for PDT of cancer.

Author Contributions: H.M.: conceptualization, acquisition, analysis of data, writing original draft, final approval. C.A.K.: conceptualization, co-supervision, writing revision and editing, final approval of version to be published. H.A.: conceptualization, supervision, writing revision and editing, funding acquisition, final approval. All authors have read and agreed to the published version of the manuscript.

Funding: This research was funded by the South African Research Chairs Initiative of the Department of Science and Technology and National Research Foundation of South Africa, grant number 98337.

Institutional Review Board Statement: Not applicable.

Informed Consent Statement: Not applicable.

Conflicts of Interest: The authors declare no conflict of interest. This manuscript is based on our original research and has neither been published, nor is being considered elsewhere for publication. Additionally, all of the authors note that they do not have any relationships that they believe could be construed as a conflict of interest with regards to the manuscript review process. The funders had no role in the design of the study; in the collection, analyses, or interpretation of data; in the writing of the manuscript, or in the decision to publish the results

\section{References}

1. Crescenzi, E.; Varriale, L.; Iovino, M.; Chiaviello, A.; Veneziani, B.M.; Palumbo, G. Photodynamic therapy with indocyanine green complements and enhances low-dose cisplatin cytotoxicity in MCF-7 breast cancer cells. Mol. Cancer Ther. 2004, 3, 537-544.

2. Karrison, T.G.; Ferguson, D.J.; Meier, P. Dormancy of Mammary Carcinoma After Mastectomy. J. Natl. Cancer Inst. 1999, 91, 80-85. [CrossRef] [PubMed]

3. Maham, A.; Tang, Z.; Wu, H.; Wang, J.; Lin, Y. Protein-Based Nanomedicine Platforms for Drug Delivery. Small 2009, 5, $1706-1721$. [CrossRef] [PubMed] 
4. Agostinis, P.; Berg, K.; Cengel, K.A.; Foster, T.H.; Girotti, A.W.; Gollnick, S.O.; Hahn, S.M.; Hamblin, M.R.; Juzeniene, A.; Kessel, D.; et al. Photodynamic therapy of cancer: An update. CA Cancer J. Clin. 2011, 61, 250-281. [CrossRef]

5. Keene, J.P.; Kessel, D.; Land, E.J.; Redmond, R.W.; Truscott, T.G. DIRECT DETECTION OF SINGLET OXYGEN SENSITIZED BY HAEMATOPORPHYRIN AND RELATED COMPOUNDS. Photochem. Photobiol. 1986, 43, 117-120. [CrossRef] [PubMed]

6. Derycke, A.S.; de Witte, P.A. Liposomes for photodynamic therapy. Adv. Drug Deliv. Rev. 2004, 56, 17-30. [CrossRef] [PubMed]

7. Banerjee, S.; MacRobert, A.; Mosse, C.; Periera, B.; Bown, S.; Keshtgar, M. Photodynamic therapy: Inception to application in breast cancer. Breast 2017, 31, 105-113. [CrossRef] [PubMed]

8. Vlastos, G.; Verkooijen, H.M. Minimally Invasive Approaches for Diagnosis and Treatment of Early-Stage Breast Cancer. Oncologist 2007, 12, 1-10. [CrossRef]

9. Mastrangelopoulou, M.; Grigalavicius, M.; Berg, K.; Ménard, M.; Theodossiou, T.A. Cytotoxic and Photocytotoxic Effects of Cercosporin on Human Tumor Cell Lines. Photochem. Photobiol. 2018, 95, 387-396. [CrossRef] [PubMed]

10. Lee, J.; Park, H.Y.; Kim, W.W.; Jeong, J.Y.; Lee, Y.-D.; Choi, M.-H.; Kim, S.; Park, J.-Y.; Jung, J.H. Combination Treatment with Photodynamic Therapy and Laser Ablation in Breast Cancer: An Animal Model Study. Photomed. Laser Surg. 2017, 35, 505-512. [CrossRef] [PubMed]

11. Gray, R.J.; Pockaj, B.A.; Garvey, E.; Blair, S. Intraoperative Margin Management in Breast-Conserving Surgery: A Systematic Review of the Literature. Ann. Surg. Oncol. 2017, 25, 18-27. [CrossRef] [PubMed]

12. Kwiatkowski, S.; Knap, B.; Przystupski, D.; Saczko, J.; Kędzierska, E.; Knap-Czop, K.; Kotlińska, J.; Michel, O.; Kotowski, K.; Kulbacka, J. Photodynamic therapy - mechanisms, photosensitizers and combinations. Biomed. Pharmacother. 2018, 106, $1098-1107$. [CrossRef] [PubMed]

13. Son, J.; Yi, G.; Yoo, J.; Park, C.; Koo, H.; Choi, H.S. Light-responsive nanomedicine for biophotonic imaging and targeted therapy. Adv. Drug Deliv. Rev. 2019, 138, 133-147. [CrossRef] [PubMed]

14. Weissleder, R. A clearer vision for in vivo imaging. Nat. Biotechnol. 2001, 19, 316-317. [CrossRef] [PubMed]

15. Smith, A.M.; Mancini, M.C.; Nie, S. Bioimaging: Second window for in vivo imaging. Nat Nanotechnol. 2009, 4(11), 710. [CrossRef] [PubMed]

16. Mazzone, G.; Russo, N.; Sicilia, E. Theoretical investigation of the absorption spectra and singlet-triplet energy gap of positively charged tetraphenylporphyrins as potential photodynamic therapy photosensitizers. Can. J. Chem. 2013, 91, 902-906. [CrossRef]

17. Yoon, I.; Li, J.Z.; Shim, Y.K. Advance in Photosensitizers and Light Delivery for Photodynamic Therapy. Clin. Endosc. 2013, 46, 7-23. [CrossRef]

18. Dobson, J.; De Queiroz, G.F.; Golding, J.P. Photodynamic therapy and diagnosis: Principles and comparative aspects. Vet. J. 2018, 233, 8-18. [CrossRef]

19. Allison, R.R.; Sibata, C.H. Oncologic photodynamic therapy photosensitizers: A clinical review. Photodiagn. Photodyn. Ther. 2010, 7, 61-75. [CrossRef]

20. Zhang, J.; Jiang, C.; Longo, J.P.F.; Azevedo, R.B.; Zhang, H.; Muehlmann, L.A. An updated overview on the development of new photosensitizers for anticancer photodynamic therapy. Acta Pharm. Sin. B 2018, 8, 137-146. [CrossRef]

21. Kessel, D.; Oleinick, N.L. Photodynamic Therapy and Cell Death Pathways. In Methods in Molecular Biology; Springer International Publishing: Cham, Switzerland, 2010; Volume 635, pp. 35-46.

22. Danhier, F.; Feron, O.; Préat, V. To exploit the tumor microenvironment: Passive and active tumor targeting of nanocarriers for anti-cancer drug delivery. J. Control. Release 2010, 148, 135-146. [CrossRef] [PubMed]

23. Pawar, P.V.; Domb, A.J.; Kumar, N. Systemic Targeting Systems-EPR Effect, Ligand Targeting Systems. In Advances in Delivery Science and Technology; Springer International Publishing: Cham, Switzerland, 2013; pp. 61-91.

24. Calixto, G.M.F.; Bernegossi, J.; De Freitas, L.M.; Fontana, C.R.; Chorilli, M. Nanotechnology-Based Drug Delivery Systems for Photodynamic Therapy of Cancer: A Review. Mol. 2016, 21, 342. [CrossRef]

25. Yoon, H.-J.; Jang, W.-D. Nanotechnology-based photodynamic therapy. J. Porphyrins Phthalocyanines 2013, 17, 16-26. [CrossRef]

26. Du, B.; Jia, S.; Wang, Q.; Ding, X.; Liu, Y.; Yao, H.; Zhou, J. A self-targeting, dual ros/ph-responsive apoferritin nanocage for spatiotemporally controlled drug delivery to breast cancer. Biomacromolecules 2018, 19, 1026-1036. [CrossRef] [PubMed]

27. Cheng, S.-H.; Lo, L.-W. Inorganic nanoparticles for enhanced photodynamic cancer therapy. Curr. Drug Discov. Technol. 2011, 8, 269-276. [CrossRef] [PubMed]

28. Colombeau, L.; Acherar, S.; Baros, F.; Arnoux, P.; Gazzali, A.M.; Zaghdoudi, K.; Toussaint, M.; Vanderesse, R.; Frochot, C. Inorganic Nanoparticles for Photodynamic Therapy. Topics in Current Chemistry 2016, 370, 113-134. [CrossRef] [PubMed]

29. Moreno-Vega, A.-I.; Gomez-Quintero, T.; Nunez-Anita, R.-E.; Acosta-Torres, L.-S.; Castaño, V. Polymeric and ceramic nanoparticles in biomedical applications. J. Nanotechnol. 2012, 2012, 1-10. [CrossRef]

30. Lee, J.; Chatterjee, D.K.; Lee, M.H.; Krishnan, S. Gold nanoparticles in breast cancer treatment: Promise and potential pitfalls. Cancer Lett. 2014, 347, 46-53. [CrossRef]

31. Penon, O.; Patiño, T.; Barrios, L.; Nogués, C.; Amabilino, D.B.; Wurst, K.; Pérez-García, L. A New Porphyrin for the Preparation of Functionalized Water-Soluble Gold Nanoparticles with Low Intrinsic Toxicity. ChemistryOpen 2014, 4, 127-136. [CrossRef]

32. Calavia, P.G.; Chambrier, I.; Cook, M.J.; Haines, A.H.; Field, R.A.; Russell, D.A. Targeted photodynamic therapy of breast cancer cells using lactose-phthalocyanine functionalized gold nanoparticles. J. Colloid Interface Sci. 2018, 512, 249-259. [CrossRef]

33. Wang, S.; Lu, G. Applications of Gold Nanoparticles in Cancer Imaging and Treatment. In Noble and Precious Metals - Properties, Nanoscale Effects and Applications; IntechOpen: London, UK, 2018. 
34. Calavia, P.G.; Bruce, G.; Pérez-García, L.; Russell, D.A. Photosensitiser-gold nanoparticle conjugates for photodynamic therapy of cancer. Photochem. Photobiol. Sci. 2018, 17, 1534-1552. [CrossRef] [PubMed]

35. Akbarzadeh, A.; Samiei, M.; Davaran, S. Magnetic nanoparticles: Preparation, physical properties, and applications in biomedicine. Nanoscale Res. Lett. 2012, 7, 144. [CrossRef]

36. Hong, E.J.; Choi, D.G.; Shim, M.S. Targeted and effective photodynamic therapy for cancer using functionalized nanomaterials. Acta Pharm. Sin. B 2016, 6, 297-307. [CrossRef] [PubMed]

37. Khan, I.; Saeed, K.; Khan, I. Nanoparticles: Properties, applications and toxicities. Arab. J. Chem. 2019, 12, 908-931. [CrossRef]

38. Valizadeh, A.; Mikaeili, H.; Samiei, M.; Farkhani, S.M.; Zarghami, N.; Kouhi, M.; Akbarzadeh, A.; Davaran, S. Quantum dots: Synthesis, bioapplications, and toxicity. Nanoscale Res. Lett. 2012, 7, 480. [CrossRef] [PubMed]

39. Punjabi, A.; Wu, X.; Tokatli-Apollon, A.; El-Rifai, M.; Lee, H.; Zhang, Y.; Wang, C.; Liu, Z.; Chan, E.M.; Duan, C.; et al. Amplifying the Red-Emission of Upconverting Nanoparticles for Biocompatible Clinically Used Prodrug-Induced Photodynamic Therapy. ACS Nano 2014, 8, 10621-10630. [CrossRef]

40. Thomas, S.C.; Harshita; Mishra, P.K.; Talegaonkar, S. Ceramic Nanoparticles: Fabrication Methods and Applications in Drug Delivery. Curr. Pharm. Des. 2015, 21, 6165-6188. [CrossRef] [PubMed]

41. Day, E.S.; Morton, J.G.; West, J.L. Nanoparticles for Thermal Cancer Therapy. J. Biomech. Eng. 2009, 131, 074001. [CrossRef] [PubMed]

42. Huang, X.; Jain, P.K.; El-Sayed, I.H.; El-Sayed, M.A. Plasmonic photothermal therapy (PPTT) using gold nanoparticles. Lasers Med. Sci. 2007, 23, 217-228. [CrossRef]

43. Li, J.-L.; Wang, L.; Liu, X.-Y.; Zhang, Z.-P.; Guo, H.-C.; Liu, W.-M.; Tang, S.-H. In vitro cancer cell imaging and therapy using transferrin-conjugated gold nanoparticles. Cancer Lett. 2009, 274, 319-326. [CrossRef] [PubMed]

44. Stuchinskaya, T.; Moreno, M.; Cook, M.J.; Edwards, D.R.; Russell, D.A. Targeted photodynamic therapy of breast cancer cells using antibody-phthalocyanine-gold nanoparticle conjugates. Photochem. Photobiol. Sci. 2011, 10, 822-831. [CrossRef]

45. Obaid, G.; Chambrier, I.; Cook, M.J.; Russell, D.A. Cancer targeting with biomolecules: A comparative study of photodynamic therapy efficacy using antibody or lectin conjugated phthalocyanine-PEG gold nanoparticles. Photochem. Photobiol. Sci. 2015, 14, 737-747. [CrossRef] [PubMed]

46. Penon, O.; Marín, M.J.; Russell, D.A.; Pérez-García, L. Water soluble, multifunctional antibody-porphyrin gold nanoparticles for targeted photodynamic therapy. J. Colloid Interface Sci. 2017, 496, 100-110. [CrossRef]

47. Yuan, H.; Fales, A.M.; Khoury, C.G.; Liu, J.; Vo-Dinh, T. Spectral characterization and intracellular detection of Surface-Enhanced Raman Scattering (SERS)-encoded plasmonic gold nanostars. J. Raman Spectrosc. 2012, 44, 234-239. [CrossRef] [PubMed]

48. Fales, A.M.; Yuan, H.; Vo-Dinh, T. Cell-penetrating peptide enhanced intracellular Raman imaging and photodynamic ther-apy. Mol. Pharm. 2013, 10, 2291-2298. [CrossRef] [PubMed]

49. Etchegoin, P.G. Quo vadis surface-enhanced Raman scattering? Phys. Chem. Chem. Phys. 2009, 11, 7348-7349. [CrossRef]

50. Dube, E.; Oluwole, D.O.; Nwaji, N.; Nyokong, T. Glycosylated zinc phthalocyanine-gold nanoparticle conjugates for photodynamic therapy: Effect of nanoparticle shape. Spectrochim. Acta Part A: Mol. Biomol. Spectrosc. 2018, 203, 85-95. [CrossRef] [PubMed]

51. Liu, J.; Liang, H.; Li, M.; Luo, Z.; Zhang, J.; Guo, X.; Cai, K. Tumor acidity activating multifunctional nanoplatform for NIR-mediated multiple enhanced photodynamic and photothermal tumor therapy. Biomaterials 2018, 157, 107-124. [CrossRef]

52. Liu, L.; Xie, H.-J.; Mu, L.-M.; Liu, R.; Su, Z.-B.; Cui, Y.-N.; Xie, Y.; Lu, W.-L. Functional chlorin gold nanorods enable to treat breast cancer by photothermal/photodynamic therapy. Int. J. Nanomed. 2018, 13, 8119-8135. [CrossRef] [PubMed]

53. Guo, R.; Shi, X. Dendrimers in Cancer Therapeutics and Diagnosis. Curr. Drug Metab. 2012, 13, 1097-1109. [CrossRef]

54. Kim, Y.; Park, E.J.; Na, D.H. Recent progress in dendrimer-based nanomedicine development. Arch. Pharmacal Res. 2018, 41, 571-582. [CrossRef] [PubMed]

55. Scott, R.W.J.; Wilson, A.O.M.; Crooks, R.M. Synthesis, Characterization, and Applications of Dendrimer-Encapsulated Nanoparticles. J. Phys. Chem. B 2005, 109, 692-704. [CrossRef]

56. Mfouo-Tynga, I.; Houreld, N.N.; Abrahamse, H. Evaluation of cell damage induced by irradiated Zinc-Phthalocyanine-gold dendrimeric nanoparticles in a breast cancer cell line. Biomed. J. 2018, 41, 254-264. [CrossRef]

57. Xu, W.; Qian, J.; Hou, G.; Wang, Y.; Wang, J.; Sun, T.; Ji, L.; Suo, A.; Yao, Y. A dual-targeted hyaluronic acid-gold nanorod platform with triple-stimuli responsiveness for photodynamic/photothermal therapy of breast cancer. Acta Biomater. 2019, 83, 400-413. [CrossRef] [PubMed]

58. Yu, W.; He, X.; Yang, Z.; Yang, X.; Xiao, W.; Liu, R.; Xie, R.; Qin, L.; Gao, H. Sequentially responsive biomimetic nanoparticles with optimal size in combination with checkpoint blockade for cascade synergetic treatment of breast cancer and lung me-tastasis. Biomaterials 2019, 217, 119309. [CrossRef]

59. Zheng, X.; Zhou, F.; Wu, B.; Chen, W.R.; Xing, D. Enhanced Tumor Treatment Using Biofunctional Indocyanine Green-Containing Nanostructure by Intratumoral or Intravenous Injection. Mol. Pharm. 2012, 9, 514-522. [CrossRef] [PubMed]

60. Schellekens, H.; Hennink, W.E.; Brinks, V. The Immunogenicity of Polyethylene Glycol: Facts and Fiction. Pharm. Res. 2013, 30, 1729-1734. [CrossRef] [PubMed]

61. Gao, W.; Hu, C.-M.J.; Fang, R.H.; Luk, B.T.; Su, J.; Zhang, L. Surface Functionalization of Gold Nanoparticles with Red Blood Cell Membranes. Adv. Mater. 2013, 25, 3549-3553. [CrossRef] [PubMed] 
62. Fang, R.H.; Hu, C.-M.J.; Zhang, L. Nanoparticles disguised as red blood cells to evade the immune system. Expert Opin. Biol. Ther. 2012, 12, 385-389. [CrossRef]

63. Jiang, Q.; Luo, Z.; Men, Y.; Yang, P.; Peng, H.; Guo, R.; Tian, Y.; Pang, Z.; Yang, W. Red blood cell membrane-camouflaged melanin nanoparticles for enhanced photothermal therapy. Biomaterials 2017, 143, 29-45. [CrossRef] [PubMed]

64. Jiang, X.-M.; Wang, L.-M.; Wang, J.; Chen, C.-Y. Gold nanomaterials: Preparation, chemical modification, biomedical appli-cations and potential risk assessment. Appl. Biochem. Biotechnol. 2012, 166, 1533-1551. [CrossRef] [PubMed]

65. Grancharov, S.G.; Zeng, H.; Sun, S.; Wang, S.X.; O’Brien, S.; Murray, C.; Kirtley, J.; Held, G. Bio-functionalization of mono-disperse magnetic nanoparticles and their use as biomolecular labels in a magnetic tunnel junction based sensor. J. Phys. Chem. B 2005, 109, 13030-13035. [CrossRef]

66. Piao, Y.; Kim, J.; Na, H.B.; Kim, D.; Baek, J.S.; Ko, M.K.; Lee, J.H.; Shokouhimehr, M.; Hyeon, T. Wrap-bake-peel process for nanostructural transformation from $\beta-\mathrm{FeOOH}$ nanorods to biocompatible iron oxide nanocapsules. Nat. Mater. $2008,7,242$. [CrossRef]

67. Narsireddy, A.; Vijayashree, K.; Irudayaraj, J.; Manorama, S.V.; Rao, N.M. Targeted in vivo photodynamic therapy with epidermal growth factor receptor-specific peptide linked nanoparticles. Int. J. Pharm. 2014, 471, 421-429. [CrossRef]

68. Choi, K.-H.; Nam, K.C.; Cho, G.; Jung, J.-S.; Park, B.J. Enhanced photodynamic anticancer activities of multifunctional mag-netic nanoparticles $\left(\mathrm{Fe}_{3} \mathrm{O}_{4}\right)$ conjugated with chlorin e6 and folic acid in prostate and breast cancer cells. Nanomaterials $2018,8,722$. [CrossRef] [PubMed]

69. Matlou, G.G.; Oluwole, D.O.; Prinsloo, E.; Nyokong, T. Photodynamic therapy activity of zinc phthalocyanine linked to folic acid and magnetic nanoparticles. J. Photochem. Photobiol. B: Biol. 2018, 186, 216-224. [CrossRef] [PubMed]

70. Dulińska-Litewka, J.; Łazarczyk, A.; Hałubiec, P.; Szafrański, O.; Karnas, K.; Karewicz, A. Superparamagnetic Iron Oxide Nanoparticles-Current and Prospective Medical Applications. Materials 2019, 12, 617. [CrossRef]

71. Khot, V.; Pawar, S. Magnetic Hyperthermia with Magnetic Nanoparticles: A Status Review. Curr. Top. Med. Chem. 2014, 14, 572-594. [CrossRef]

72. Duguet, E.; Vasseur, S.; Mornet, S.; Devoisselle, J.-M. Magnetic nanoparticles and their applications in medicine. Nanomedicine 2006, 1, 157-168. [CrossRef] [PubMed]

73. Zottel, A.; Paska, A.V.; Jovčevska, I. Nanotechnology Meets Oncology: Nanomaterials in Brain Cancer Research, Diagnosis and Therapy. Materials 2019, 12, 1588. [CrossRef]

74. Kolosnjaj-Tabi, J.; Wilhelm, C. Magnetic nanoparticles in cancer therapy: How can thermal approaches help? Nanomedicine 2017, 12, 573-575. [CrossRef] [PubMed]

75. Kolosnjaj-Tabi, J.; Di Corato, R.; Lartigue, L.; Marangon, I.; Guardia, P.; Silva, A.K.A.; Luciani, N.; Clément, O.; Flaud, P.; Singh, J.V.; et al. Heat-Generating Iron Oxide Nanocubes: Subtle “Destructurators” of the Tumoral Microenvironment. ACS Nano 2014, 8, 4268-4283. [CrossRef]

76. Hong, G.; Diao, S.; Antaris, A.L.; Dai, H. Carbon Nanomaterials for Biological Imaging and Nanomedicinal Therapy. Chem. Rev. 2015, 115, 10816-10906. [CrossRef]

77. Huang, P.; Wang, S.; Wang, X.; Shen, G.; Lin, J.; Wang, Z.; Guo, S.; Cui, D.; Yang, M.; Chen, X. Surface Functionalization of Chemically Reduced Graphene Oxide for Targeted Photodynamic Therapy. J. Biomed. Nanotechnol. 2015, 11, 117-125. [CrossRef] [PubMed]

78. Liu, Q.; Xu, L.; Zhang, X.; Li, N.; Zheng, J.; Guan, M.; Fang, X.; Wang, C.; Shu, C. Enhanced Photodynamic Efficiency of an Aptamer-Guided Fullerene Photosensitizer toward Tumor Cells. Chem. Asian J. 2013, 8, 2370-2376. [CrossRef] [PubMed]

79. Mosinger, J.; Lang, K.; Kubát, P. Photoactivatable Nanostructured Surfaces for Biomedical Applications. In Topics in Current Chemistry; Springer International Publishing: Cham, Switzerland, 2016; Volume 370, pp. 135-168.

80. Shi, J.; Wang, L.; Gao, J.; Liu, Y.; Zhang, J.; Ma, R.; Liu, R.; Zhang, Z. A fullerene-based multi-functional nanoplatform for cancer theranostic applications. Biomaterials 2014, 35, 5771-5784. [CrossRef]

81. Tian, B.; Wang, C.; Zhang, S.; Feng, L.; Liu, Z. Photothermally Enhanced Photodynamic Therapy Delivered by Nano-Graphene Oxide. ACS Nano 2011, 5, 7000-7009. [CrossRef]

82. Gao, L.; Zhang, C.; Gao, D.; Liu, H.; Yu, X.; Lai, J.; Wang, F.; Lin, J.; Liu, Z. Enhanced Anti-Tumor Efficacy through a Combination of Integrin $\alpha \mathrm{v} \beta 6$-Targeted Photodynamic Therapy and Immune Checkpoint Inhibition. Theranostics 2016, 6, 627-637. [CrossRef] [PubMed]

83. Yu, X.; Gao, D.; Gao, L.; Lai, J.; Zhang, C.; Zhao, Y.; Zhong, L.; Jia, B.; Wang, F.; Chen, X.; et al. Inhibiting Metastasis and Preventing Tumor Relapse by Triggering Host Immunity with Tumor-Targeted Photodynamic Therapy Using PhotosensitizerLoaded Functional Nanographenes. ACS Nano 2017, 11, 10147-10158. [CrossRef] [PubMed]

84. Yamakoshi, Y.; Umezawa, N.; Ryu, A.; Arakane, K.; Miyata, N.; Goda, Y.; Masumizu, T.; Nagano, T. Active Oxygen Species Generated from Photoexcited Fullerene $\left(\mathrm{C}_{60}\right)$ as Potential Medicines: $\mathrm{O}_{2}{ }^{-\bullet}$ versus ${ }^{1} \mathrm{O}_{2}$. J. Am. Chem. Soc. 2003, 125, 12803-12809. [CrossRef]

85. Murakami, T.; Nakatsuji, H.; Inada, M.; Matoba, Y.; Umeyama, T.; Tsujimoto, M.; Isoda, S.; Hashida, M.; Imahori, H. Photodynamic and photothermal effects of semiconducting and metallic-enriched single-walled carbon nanotubes. J. Am. Chem. Soc. 2012, 134, 17862-17865. [CrossRef] [PubMed] 
86. Zakharian, T.Y.; Seryshev, A.; Sitharaman, B.; Gilbert, B.E.; Knight, V.; Wilson, L.J. A Fullerene-Paclitaxel Chemotherapeutic: Synthesis, Characterization, and Study of Biological Activity in Tissue Culture. J. Am. Chem. Soc. 2005, 127, 12508-12509. [CrossRef] [PubMed]

87. Sharma, S.K.; Chiang, L.Y.; Hamblin, M.R. Photodynamic therapy with fullerenes in vivo: Reality or a dream? Nanomedicine 2011, 6, 1813-1825. [CrossRef] [PubMed]

88. Wolfram, J.; Zhu, M.; Yang, Y.; Shen, J.; Gentile, E.; Paolino, D.; Fresta, M.; Nie, G.; Chen, C.; Shen, H.; et al. Safety of Nanoparticles in Medicine. Curr. Drug Targets 2015, 16, 1671-1681. [CrossRef] [PubMed]

89. Kamila, S.; McEwan, C.; Costley, D.; Atchison, J.; Sheng, Y.; Hamilton, G.R.C.; Fowley, C.; Callan, J.F. Diagnostic and Therapeutic Applications of Quantum Dots in Nanomedicine. In Topics in Current Chemistry; Springer International Publishing: Cham, Switzerland, 2016; Volume 370, pp. 203-224.

90. Tripathi, S.K.; Kaur, G.; Khurana, R.K.; Kapoor, S.; Singh, B. Quantum Dots and their Potential Role in Cancer Theranostics. Crit. Rev. Ther. Drug Carr. Syst. 2015, 32, 461-502. [CrossRef] [PubMed]

91. Samia, A.C.S.; Dayal, S.; Burda, C. Quantum Dot-based Energy Transfer: Perspectives and Potential for Applications in Photodynamic Therapy. Photochem. Photobiol. 2006, 82, 617-625. [CrossRef]

92. Monroe, J.D.; Belekov, E.; Er, A.O.; Smith, M.E. Anticancer Photodynamic Therapy Properties of Sulfur-Doped Graphene Quantum Dot and Methylene Blue Preparations in MCF-7 Breast Cancer Cell Culture. Photochem. Photobiol. 2019, 95, 1473-1481. [CrossRef]

93. Nene, L.C.; Managa, M.E.; Oluwole, D.O.; Mafukidze, D.M.; Sindelo, A.; Nyokong, T. The photo-physicochemical properties and in vitro photodynamic therapy activity of differently substituted-zinc (II)-phthalocyanines and graphene quantum dots conjugates on MCF7 breast cancer cell line. Inorganica Chim. Acta 2019, 488, 304-311. [CrossRef]

94. Anas, A.; Akita, H.; Harashima, H.; Itoh, T.; Ishikawa, M.; Biju, V. Photosensitized breakage and damage of DNA by CdSe-ZnS quantum dots. J. Phys. Chem. B 2008, 112, 10005-10011. [CrossRef]

95. Kievit, F.M.; Zhang, M. Cancer nanotheranostics: Improving imaging and therapy by targeted delivery across biological bar-riers. Adv. Mater. 2011, 23, H217-H247. [CrossRef]

96. Yong, K.-T.; Ding, H.; Roy, I.; Law, W.-C.; Bergey, E.J.; Maitra, A.; Prasad, P.N. Imaging Pancreatic Cancer Using Bioconjugated InP Quantum Dots. ACS Nano 2009, 3, 502-510. [CrossRef] [PubMed]

97. Bilan, R.; Nabiev, I.; Sukhanova, A. Quantum Dot-Based Nanotools for Bioimaging, Diagnostics, and Drug Delivery. ChemBioChem 2016, 17, 2103-2114. [CrossRef]

98. Weng, K.C.; Noble, C.O.; Papahadjopoulos-Sternberg, B.; Chen, F.F.; Drummond, D.C.; Kirpotin, D.B.; Wang, D.; Hom, Y.K.; Hann, B.; Park, J.W. Targeted tumor cell internalization and imaging of multifunctional quantum dot-conjugated immu-noliposomes in vitro and in vivo. Nano Lett. 2008, 8, 2851-2857. [CrossRef]

99. Zrazhevskiy, P.; Sena, M.; Gao, X. Designing multifunctional quantum dots for bioimaging, detection, and drug delivery. Chem. Soc. Rev. 2010, 39, 4326-4354. [CrossRef] [PubMed]

100. Mai, W.X.; Meng, H. Mesoporous silica nanoparticles: A multifunctional nano therapeutic system. Integr. Biol. 2013, 5, 19-28. [CrossRef] [PubMed]

101. Chen, Y.-C.; Huang, X.-C.; Luo, Y.-L.; Chang, Y.-C.; Hsieh, Y.-Z.; Hsu, H.-Y. Non-metallic nanomaterials in cancer theranostics: A review of silica- and carbon-based drug delivery systems. Sci. Technol. Adv. Mater. 2013, 14, 044407. [CrossRef] [PubMed]

102. Brevet, D.; Gary-Bobo, M.; Raehm, L.; Richeter, S.; Hocine, O.; Amro, K.; Loock, B.; Couleaud, P.; Frochot, C.; Morère, A.; et al. Mannose-targeted mesoporous silica nanoparticles for photodynamic therapy. Chem. Commun. 2009, 1475-1477. [CrossRef] [PubMed]

103. Zou, Q.; Zhao, H.; Zhao, Y.; Fang, Y.; Chen, D.; Ren, J.; Wang, X.; Wang, Y.; Gu, Y.; Wu, F. Effective Two-Photon Excited Photodynamic Therapy of Xenograft Tumors Sensitized by Water-Soluble Bis(arylidene)cycloalkanone Photosensitizers. J. Med. Chem. 2015, 58, 7949-7958. [CrossRef] [PubMed]

104. Pawlicki, M.; Collins, H.A.; Denning, R.G.; Anderson, H.L. Two-Photon Absorption and the Design of Two-Photon Dyes. Angew. Chem. Int. Ed. 2009, 48, 3244-3266. [CrossRef] [PubMed]

105. Shanmugam, V.; Selvakumar, S.; Yeh, C.-S. Near-infrared light-responsive nanomaterials in cancer therapeutics. Chem. Soc. Rev. 2014, 43, 6254-6287. [CrossRef]

106. Starkey, J.R.; Rebane, A.K.; Drobizhev, M.A.; Meng, F.; Gong, A.; Elliott, A.; McInnerney, K.; Spangler, C.W. New Two-Photon Activated Photodynamic Therapy Sensitizers Induce Xenograft Tumor Regressions after Near-IR Laser Treatment through the Body of the Host Mouse. Clin. Cancer Res. 2008, 14, 6564-6573. [CrossRef] [PubMed]

107. Shen, X.; Li, S.; Li, L.; Yao, S.Q.; Xu, Q.H. Highly Efficient, Conjugated-Polymer-Based Nano-Photosensitizers for Selectively Targeted Two-Photon Photodynamic Therapy and Imaging of Cancer Cells. Chem. Eur. J 2015, 21, 2214-2221. [CrossRef] [PubMed]

108. Qian, J.; Wang, D.; Cai, F.; Zhan, Q.; Wang, Y.; He, S. Photosensitizer encapsulated organically modified silica nanoparticles for direct two-photon photodynamic therapy and In Vivo functional imaging. Biomaterials 2012, 33, 4851-4860. [CrossRef] [PubMed]

109. Park, Y.I.; Lee, K.T.; Suh, Y.D.; Hyeon, T. Upconverting nanoparticles: A versatile platform for wide-field two-photon mi-croscopy and multi-modal in vivo imaging. Chem. Soc. Rev. 2015, 44, 1302-1317. [CrossRef] [PubMed]

110. Shen, Y.; Shuhendler, A.J.; Ye, D.; Xu, J.-J.; Chen, H.-Y. Two-photon excitation nanoparticles for photodynamic therapy. Chem. Soc. Rev. 2016, 45, 6725-6741. [CrossRef] [PubMed] 
111. Denk, W.; Strickler, J.H.; Webb, W.W. Two-photon laser scanning fluorescence microscopy. Science 1990, 248, 73-76. [CrossRef]

112. Secret, E.; Maynadier, M.; Gallud, A.; Chaix, A.; Bouffard, E.; Gary-Bobo, M.; Marcotte, N.; Mongin, O.; El Cheikh, K.; Hugues, V.; et al. Two-Photon Excitation of Porphyrin-Functionalized Porous Silicon Nanoparticles for Photodynamic Therapy. Adv. Mater. 2014, 26, 7643-7648. [CrossRef]

113. Park, J.-H.; Gu, L.; Von Maltzahn, G.; Ruoslahti, E.; Bhatia, S.N.; Sailor, M.J. Biodegradable luminescent porous silicon nanoparticles for in vivo applications. Nat. Mater. 2009, 8, 331-336. [CrossRef] [PubMed]

114. Cao, B.; Yang, M.; Zhu, Y.; Qu, X.; Mao, C. Stem Cells Loaded with Nanoparticles as a Drug Carrier for In Vivo Breast Cancer Therapy. Adv. Mater. 2014, 26, 4627-4631. [CrossRef]

115. Kidd, S.; Spaeth, E.; Dembinski, J.L.; Dietrich, M.; Watson, K.; Klopp, A.; Battula, V.L.; Weil, M.; Andreeff, M.; Marini, F.C. Direct Evidence of Mesenchymal Stem Cell Tropism for Tumor and Wounding Microenvironments Using In Vivo Bioluminescent Imaging. Stem Cells 2009, 27, 2614-2623. [CrossRef]

116. Ren, Y.-J.; Zhang, H.; Huang, H.; Wang, X.-M.; Zhou, Z.-Y.; Cui, F.-Z.; An, Y.-H. In vitro behavior of neural stem cells in response to different chemical functional groups. Biomater. 2009, 30, 1036-1044. [CrossRef]

117. Zhu, H.; Cao, B.; Zhen, Z.; Laxmi, A.A.; Li, D.; Liu, S.; Mao, C. Controlled growth and differentiation of MSCs on grooved films assembled from monodisperse biological nanofibers with genetically tunable surface chemistries. Biomater. 2011, 32, 4744-4752. [CrossRef] [PubMed]

118. Sonabend, A.M.; Ulasov, I.V.; Tyler, M.A.; Rivera, A.A.; Mathis, J.M.; Lesniak, M.S. Mesenchymal Stem Cells Effectively Deliver an Oncolytic Adenovirus to Intracranial Glioma. STEM CELLS 2008, 26, 831-841. [CrossRef] [PubMed]

119. Bharathiraja, S.; Moorthy, M.S.; Manivasagan, P.; Seo, H.; Lee, K.D.; Oh, J. Chlorin e6 conjugated silica nanoparticles for targeted and effective photodynamic therapy. Photodiagn. Photodyn. Ther. 2017, 19, 212-220. [CrossRef]

120. Yuan, A.; Wu, J.; Tang, X.; Zhao, L.; Xu, F.; Hu, Y. Application of Near-Infrared Dyes for Tumor Imaging, Photothermal, and Photodynamic Therapies. J. Pharm. Sci. 2013, 102, 6-28. [CrossRef] [PubMed]

121. Ntziachristos, V.; Bremer, C.; Weissleder, R. Fluorescence imaging with near-infrared light: New technological advances that enable in vivo molecular imaging. Eur. Radiol. 2003, 13, 195-208. [CrossRef] [PubMed]

122. Hu, J.; Tang, Y.; Elmenoufy, A.H.; Xu, H.; Cheng, Z.; Yang, X. Nanocomposite-Based Photodynamic Therapy Strategies for Deep Tumor Treatment. Small 2015, 11, 5860-5887. [CrossRef] [PubMed]

123. Bulin, A.-L.; Truillet, C.; Chouikrat, R.; Lux, F.; Frochot, C.; Amans, D.; LeDoux, G.; Tillement, O.; Perriat, P.; Barberi-Heyob, M.; et al. X-ray-Induced Singlet Oxygen Activation with Nanoscintillator-Coupled Porphyrins. J. Phys. Chem. C 2013, 117, 21583-21589. [CrossRef]

124. Chen, H.; Wang, G.D.; Chuang, Y.-J.; Zhen, Z.; Chen, X.; Biddinger, P.; Hao, Z.; Liu, F.; Shen, B.; Pan, Z. Nanoscintilla-tor-mediated X-ray inducible photodynamic therapy for in vivo cancer treatment. Nano Lett. 2015, 15, 2249-2256. [CrossRef]

125. Kaščáková, S.; Giuliani, A.; Lacerda, S.; Pallier, A.; Mercère, P.; Tóth, É.; Réfrégiers, M. X-ray-induced radiophotodynamic therapy (RPDT) using lanthanide micelles: Beyond depth limitations. Nano Res. 2015, 8, 2373-2379. [CrossRef]

126. Sengar, P.; Juárez, P.; Verdugo-Meza, A.; Arellano, D.L.; Jain, A.; Chauhan, K.; Hirata, G.A.; Fournier, P.G.J. Development of a functionalized UV-emitting nanocomposite for the treatment of cancer using indirect photodynamic therapy. J. Nanobiotechnol. 2018, 16, 1-19. [CrossRef] [PubMed]

127. Ramimoghadam, D.; Bagheri, S.; Abd Hamid, S.B. Biotemplated synthesis of anatase titanium dioxide nanoparticles via lignocellulosic waste material. BioMed Res. Int. 2014, 2014, 1-7. [CrossRef]

128. Kitsiou, P.; Lagopati, N.; Tsilibary, E.-P.; Falaras, P.; Papazafiri, P.; Pavlatou, E.P.; Kotsopoulou, E. Effect of nanostructured TiO 2 crystal phase on photoinduced apoptosis of breast cancer epithelial cells. Int. J. Nanomed. 2014, 9, 3219-3230. [CrossRef] [PubMed]

129. Gangopadhyay, M.; Mukhopadhyay, S.K.; Karthik, S.; Barman, S.; Singh, N.D.P. Targeted photoresponsive $\mathrm{TiO}_{2}-\mathrm{coumarin}$ nanoconjugate for efficient combination therapy in MDA-MB-231 breast cancer cells: Synergic effect of photodynamic therapy (PDT) and anticancer drug chlorambucil. MedChemComm 2015, 6, 769-777. [CrossRef]

130. Zholobak, N.; Ivanov, V.; Shcherbakov, A.; Shaporev, A.; Polezhaeva, O.; Baranchikov, A.; Spivak, N.; Tretyakov, Y. UV-shielding property, photocatalytic activity and photocytotoxicity of ceria colloid solutions. J. Photochem. Photobiol. B: Biol. 2011, 102, 32-38. [CrossRef] [PubMed]

131. Asati, A.; Santra, S.; Kaittanis, C.; Nath, S.; Perez, J.M. Oxidase-Like Activity of Polymer-Coated Cerium Oxide Nanoparticles. Angew. Chem. Int. Ed. 2009, 48, 2308-2312. [CrossRef] [PubMed]

132. Culcasi, M.; Benameur, L.; Mercier, A.; Lucchesi, C.; Rahmouni, H.; Asteian, A.; Casano, G.; Botta, A.; Kovacic, H.; Pietri, S. EPR spin trapping evaluation of ROS production in human fibroblasts exposed to cerium oxide nanoparticles: Evidence for NADPH oxidase and mitochondrial stimulation. Chem.-Biol. Interact. 2012, 199, 161-176. [CrossRef] [PubMed]

133. RajeshKumar, S.; Naik, P. Synthesis and biomedical applications of Cerium oxide nanoparticles-A Review. Biotechnol. Rep. 2018, 17, 1-5. [CrossRef] [PubMed]

134. Li, H.; Liu, C.; Zeng, Y.-P.; Hao, Y.-H.; Huang, J.-W.; Yang, Z.-Y.; Li, R. Nanoceria-mediated drug delivery for targeted photodynamic therapy on drug-resistant breast cancer. ACS Appl. Mater. Interfaces 2016, 8, 31510-31523. [CrossRef]

135. Vanneman, M.; Dranoff, G. Combining immunotherapy and targeted therapies in cancer treatment. Nat. Rev. Cancer 2012, 12, 237-251. [CrossRef] [PubMed]

136. Couzin-Frankel, J. Cancer Immunotherapy. Science 2013, 342, 1432-1433. [CrossRef] 
137. Rooney, M.S.; Shukla, S.A.; Wu, C.J.; Getz, G.; Hacohen, N. Molecular and Genetic Properties of Tumors Associated with Local Immune Cytolytic Activity. Cell 2015, 160, 48-61. [CrossRef] [PubMed]

138. Schumacher, T.N.; Schreiber, R.D. Neoantigens in cancer immunotherapy. Science 2015, 348, 69-74. [CrossRef]

139. Duan, X.; Chan, C.; Guo, N.; Han, W.; Weichselbaum, R.R.; Lin, W. Photodynamic Therapy Mediated by Nontoxic Core-Shell Nanoparticles Synergizes with Immune Checkpoint Blockade To Elicit Antitumor Immunity and Antimetastatic Effect on Breast Cancer. J. Am. Chem. Soc. 2016, 138, 16686-16695. [CrossRef] [PubMed]

140. Wang, F.; Banerjee, D.; Liu, Y.; Chen, X.; Liu, X. Upconversion nanoparticles in biological labeling, imaging, and therapy. Analyst 2010, 135, 1839-1854. [CrossRef] [PubMed]

141. Mader, H.S.; Kele, P.; Saleh, S.M.; Wolfbeis, O.S. Upconverting luminescent nanoparticles for use in bioconjugation and bioimaging. Curr. Opin. Chem. Biol. 2010, 14, 582-596. [CrossRef]

142. Wang, B.-Y.; Liao, M.-L.; Hong, G.-C.; Chang, W.-W.; Chu, C.-C. Near-Infrared-Triggered Photodynamic Therapy toward Breast Cancer Cells Using Dendrimer-Functionalized Upconversion Nanoparticles. Nanomaterials 2017, 7, 269. [CrossRef] [PubMed]

143. Zeng, L.; Pan, Y.; Zou, R.; Zhang, J.; Tian, Y.; Teng, Z.; Wang, S.; Ren, W.; Xiao, X.; Zhang, L.; et al. 808 nm-excited upconversion nanoprobes with low heating effect for targeted magnetic resonance imaging and high-efficacy photodynamic therapy in HER2-overexpressed breast cancer. Biomaterials 2016, 103, 116-127. [CrossRef] [PubMed]

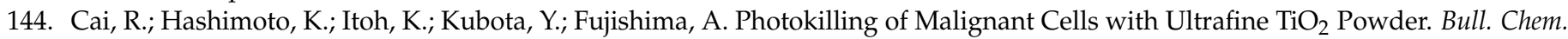
Soc. Jpn. 1991, 64, 1268-1273. [CrossRef]

145. Wang, K.; Qincheng, W.; Wang, F.; Bai, S.; Li, S.; Li, Z. Coating a N-doped $\mathrm{TiO}_{2}$ shell on dually sensitized upconversion nanocrystals to provide NIR-enhanced photocatalysts for efficient utilization of upconverted emissions. Inorg. Chem. Front. 2016, 3, 1190-1197. [CrossRef]

146. Fujishima, A.; Honda, K. Electrochemical Photolysis of Water at a Semiconductor Electrode. Nat. Cell Biol. 1972, $238,37-38$. [CrossRef] [PubMed]

147. Zeng, L.; Pan, Y.; Tian, Y.; Wang, X.; Ren, W.; Wang, S.; Lu, G.; Wu, A. Doxorubicin-loaded NaYF4:Yb/Tm-TiO 2 inorganic photosensitizers for NIR-triggered photodynamic therapy and enhanced chemotherapy in drug-resistant breast cancers. Biomaterials 2015, 57, 93-106. [CrossRef]

148. Yu, Z.; Ge, Y.; Sun, Q.; Pan, W.; Wan, X.; Li, N.; Tang, B. A pre-protective strategy for precise tumor targeting and efficient photodynamic therapy with a switchable DNA/upconversion nanocomposite. Chem. Sci. 2018, 9, 3563-3569. [CrossRef]

149. Blanco, E.; Shen, H.; Ferrari, M. Principles of nanoparticle design for overcoming biological barriers to drug delivery. Nat. Biotechnol. 2015, 33, 941-951. [CrossRef]

150. Kettiger, H.; Schipanski, A.; Wick, P.; Huwyler, J. Engineered nanomaterial uptake and tissue distribution: From cell to or-ganism. Int. J. Nanomed. 2013, 8, 3255.

151. Yu, Z.; Xia, Y.; Xing, J.; Li, Z.; Zhen, J.; Jin, Y.; Tian, Y.; Liu, C.; Jiang, Z.; Li, J. Y 1-receptor-ligand-functionalized ultrasmall up-conversion nanoparticles for tumor-targeted trimodality imaging and photodynamic therapy with low toxicity. Nanoscale 2018, 10, 17038-17052. [CrossRef] [PubMed]

152. Ramírez-García, G.; Panikar, S.S.; López-Luke, T.; Piazza, V.; Honorato-Colin, M.A.; Camacho-Villegas, T.; Hernández-Gutiérrez, R.; De La Rosa-Cruz, E. An immunoconjugated up-conversion nanocomplex for selective imaging and photodynamic therapy against HER2-positive breast cancer. Nanoscale 2018, 10, 10154-10165. [CrossRef]

153. Ramírez-García, G.; De la Rosa, E.; López-Luke, T.; Panikar, S.S.; Salas, P. Controlling trapping states on selective theranostic core@ shell (NaYF4:Yb,Tm@TiO $-\mathrm{ZrO}_{2}$ ) nanocomplexes for enhanced NIR-activated photodynamic therapy against breast cancer cells. Dalton Trans. 2019, 48, 9962-9973. [CrossRef]

154. Pirzada, B.M.; Mir, N.A.; Qutub, N.; Mehraj, O.; Sabir, S.; Muneer, M. Synthesis, characterization and optimization of photocatalytic activity of $\mathrm{TiO}_{2} / \mathrm{ZrO}_{2}$ nanocomposite heterostructures. Mater. Sci. Eng. B 2015, 193, 137-145. [CrossRef]

155. Xu, A.-W.; Gao, Y.; Liu, H.-Q. The Preparation, Characterization, and their Photocatalytic Activities of Rare-Earth-Doped TiO 2 Nanoparticles. J. Catal. 2002, 207, 151-157. [CrossRef]

156. Feng, Y.; Wu, Y.; Zuo, J.; Tu, L.; Que, I.; Chang, Y.; Cruz, L.J.; Chan, A.; Zhang, H. Assembly of upconversion nanophoto-sensitizer in vivo to achieve scatheless real-time imaging and selective photodynamic therapy. Biomaterials 2019, 201, 33-41. [CrossRef] [PubMed]

157. Guo, Y.; Kumar, M.; Zhang, P. Nanoparticle-Based Photosensitizers under CW Infrared Excitation. Chem. Mater. 2007, 19, 6071-6072. [CrossRef] [PubMed]

158. Lucky, S.S.; Soo, K.C.; Zhang, Y. Nanoparticles in Photodynamic Therapy. Chem. Rev. 2015, 115, 1990-2042. [CrossRef] [PubMed]

159. Huang, Y.-Y.; Sharma, S.K.; Dai, T.; Chung, H.; Yaroslavsky, A.; Garcia-Diaz, M.; Chang, J.; Chiang, L.Y.; Hamblin, M.R. Can nanotechnology potentiate photodynamic therapy? Nanotechnol. Rev. 2012, 1, 111-146. [CrossRef] [PubMed] 